\title{
VISIOCONFERENSING TECHNOLOGY AND THE RIGHT TO A FAIR TRIAL
}

\author{
Lynda MABROUK ${ }^{1}$
}

\section{Istanbul: Türkiye \\ p. $385-401$}

Received: $27 / 11 / 2021$

Accepted: $18 / 12 / 2021$

Published: 01/01/2022

This article has been scanned I iThenticat No plagiarism detected

\section{Abstract:}

The diffusion of communication and information technologies and their great development in recent years have had a great impact on all aspects of life, including the justice sector, through what is called the electronic court or electronic dispute resolution. The intrusion of this technology in the area of justice has had great success, particularly with regard to the speed of dispute settlement, the reduction in the load of cases and their accumulation or the displacement of litigants before the courts. The videoconferencing technology adopted by the courts has led to a number of modifications in the working methods of the judge as well as in the rights of the parties, particularly in criminal matters. This technology has changed the characteristics of the traditional trial and affected the principles and guarantees of a fair trial.

Key words: Traditional Trial, Video Conferencing Technology, Principles of Fair Trial, Rights of Defence, The Presence, The Public, Oral, The Right to Judge, Parties To The Case, Protection of Human Rights, The Justice. 


\section{تقنية التحاضر المئي والحق في محاكمة عادلة}

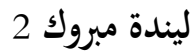

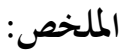

كان لانتشار تكنولوجيا الاتصالات والمعلومات وتطورها الكبير في السنوات الأخيرة أثرها البالغ، فلقد هيمنت

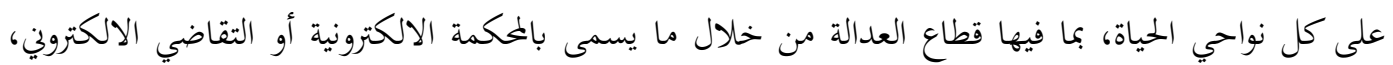

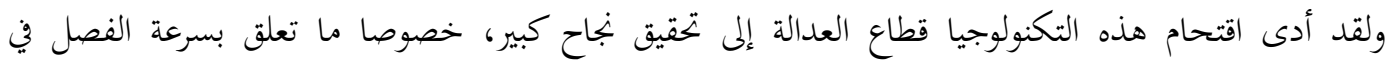
المنازعات وتتفيف عبء تراكم القضايا وتنقل المتقاضين إلى المحاكم لكن في نفس الوقت أفرزت هذه التكنولوجية عدد من التعديلات في أساليب عمل القاضي، وكذلك في حقوق الأطراف خصوصا في الدعوى الجزائية بعد تبني

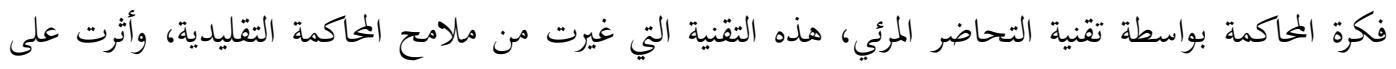

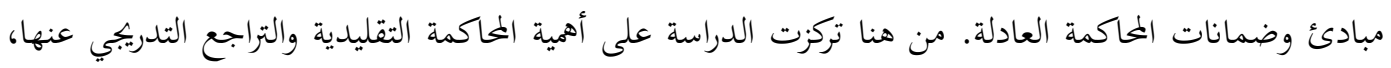

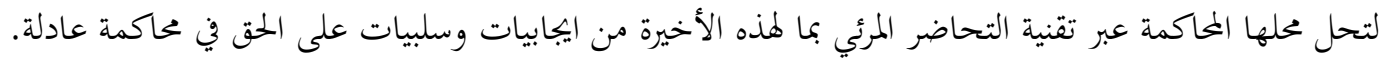

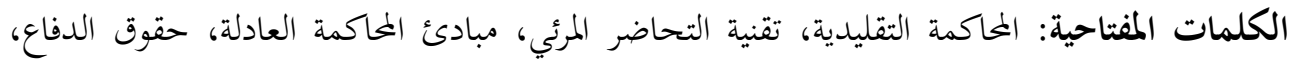
الحضورية، العلنية، الشفوية، الحق في القاضي، أطراف الدعوى، حماية حقوق الإنسان، العدالة.

لقد أفرزت الثورة الرقمية التي يشهدها العالم، تطورا كبيرا على جميع الأصعدة والنواحي دوليا ومحليا. وهيمنت على كل

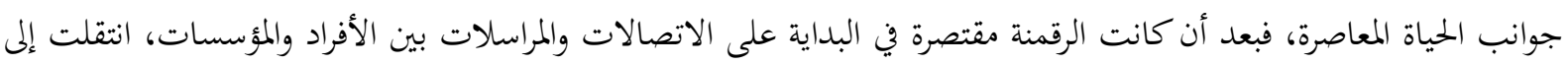

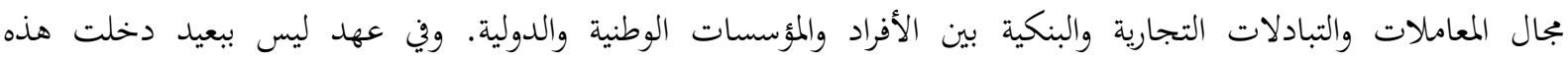

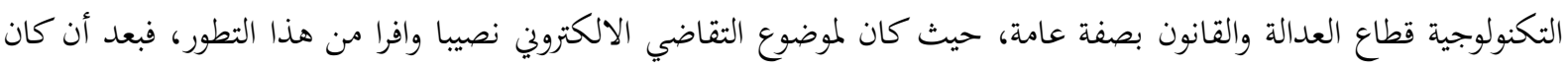

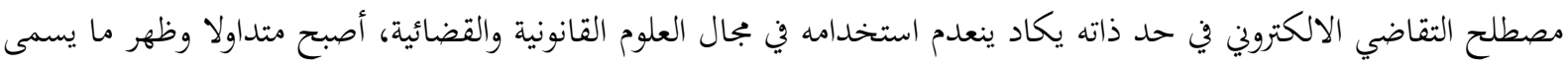
بالمكمة الالكترونية كواحدة من نتائج الحكومة الالكترونية، ليحدث تغييرا كبيرا في إجراءات التقاضي التقليدية، حيث التهت

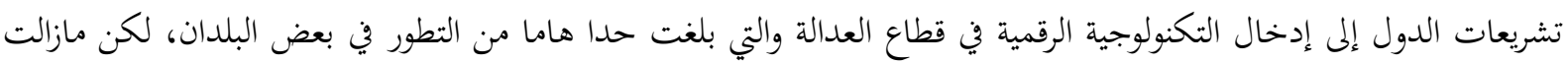

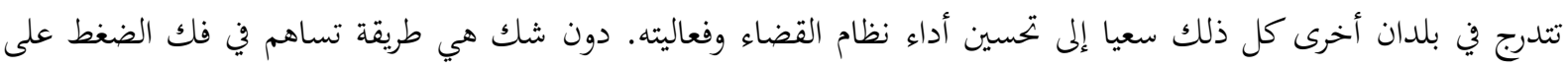

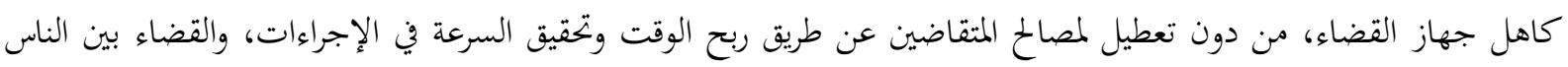

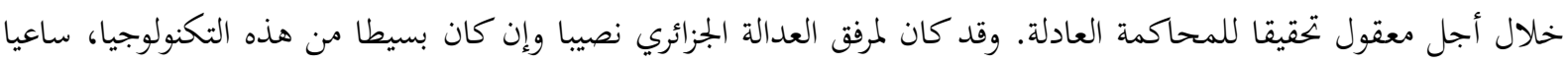
نهو مسايرة التوجه العالمي في هذا المجال، حتى يتسنى لهذا المرفق الحساس من مواجهة التحديات، ومواكبة ما ينجر عن هذه

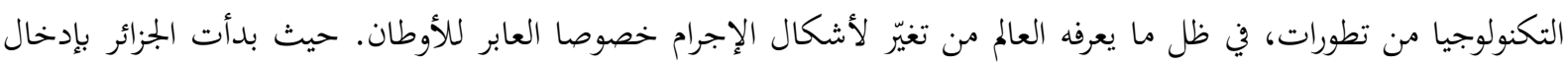

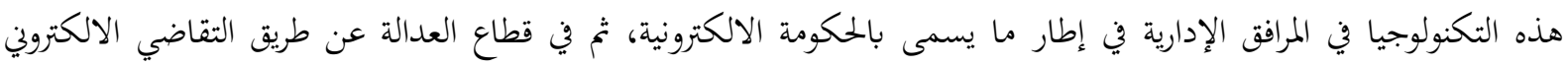
بواسطة ما يسمى بقانون عصرنة العدالة، واستخدام آلية التحاضر المرئي عن بعد، والتي يقابلها باللغة الفرنسية مصطيلح 
"Visio-conférence" جلسات المحاكمة وتوسع استخدامها أكثر في ظل جائحة كوفيد 19. وإذ ندرس المحاكمة عبر تقنية التحاضر المرئي فإننا نسلط الضوء على هذا الأسلوب الجلديد في الإجراءات أمام القضاء

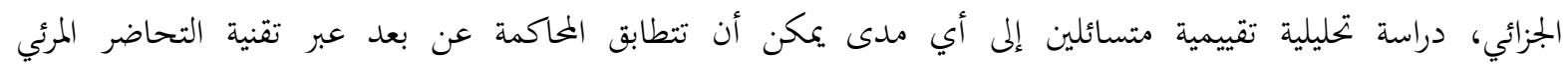
Visioconférence بها من ضمانات، هي محور النظم الرسمية والرمزية والعملية لتحقيق العدالة، ونتساءل أيضا كيف تنجح العدالة البعيدة في ترسيخ نفسها كبديل للعدالة الحضورية؟ وهل تتحقق فعلا الحماية اللازمة والاحترام الكافي للحقوق والحريات في الحالة التي يقدم فيها

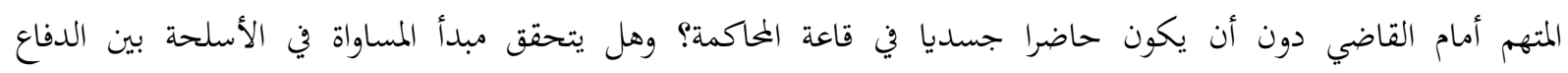

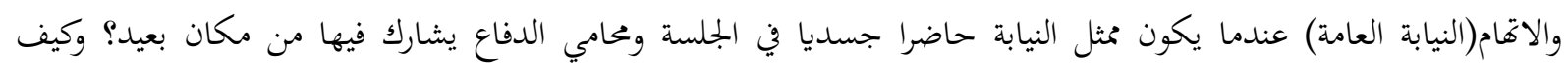
ساهم تقنية التحاضر المرئي عن بعد وأثرت في تحقيق المحاكمة العادلة؟ وما هي أهم التحديات التي تواجه تطبيق هذه التهائ التقنية؟ هذه الأسئلة التي يحددها هذا البحث للإجابة عليها، تكون من خلال تحليل ديناميكيات نشأة هذا الابتكار وتطويره

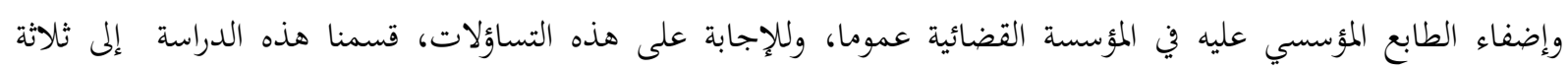
مباحث كما يلي:

- - المبحث الأول: الانتقال من المحاكمة التقليدية إلى المحاكمة الرقمية. - - - المبحث الثاني: تأثير تقنية التحاضر المئي على الحق في محاكمة عادلة. - - ملمبحث الثالث: تطابق تقنية التحاضر المرئي مع الحقى في المحاكمة العادلة. 


\section{المبحث الأول: الانتقال من المحاكمة التقليدية إلى المحاكمة الرقمية}

تعد الدعوى الجنائية إحدى حلقات الشرعية، لما تنطوي عليه من ضمان إجراء محاكمة عادلة للفصل في إدانة الفرد من

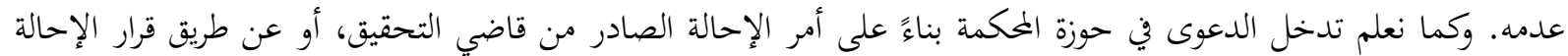

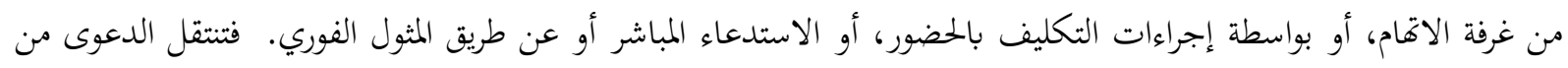

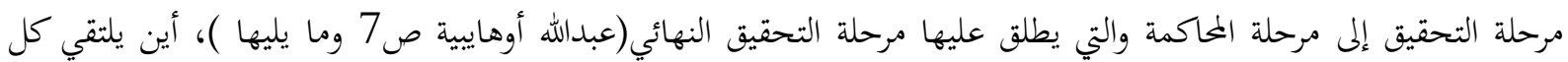
الخصوم في جلسة المحاكمة بمفهومها التقليدي، هذا المفهوم الذي بدأ في الآونة الأخيرة يشهد تغيرّات جذرية، طالته كما طالت قطاع العدالة عموما وجلسة المحاكمة خصوصا، بما تحمله هذه الأخيرة من رمزية وطقوس وهيبة استمرت في الزمن إلى يومنا هذا.

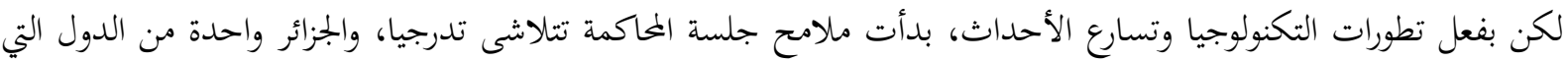

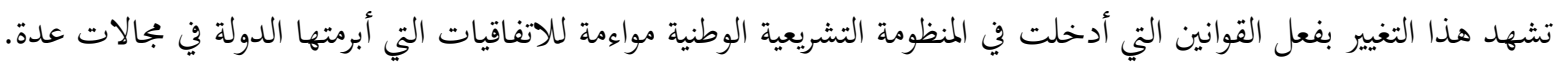

\section{المطلب الأول: بداية التراجع عن المحاكمة التقليدية}

مرت المحاكمة الجنائية أو ما يطلق عليها (بالتحقيق النهائي)، بمحطات أساسية كانت ومازالت تتمحور حول جلسة المحاكمة التقليدية، التي ترتكز على البعد المسرحي وهو الطابع الأصلي والمستمر في التنظيم القضائي المعاصر، رغم القيود المتزايدة

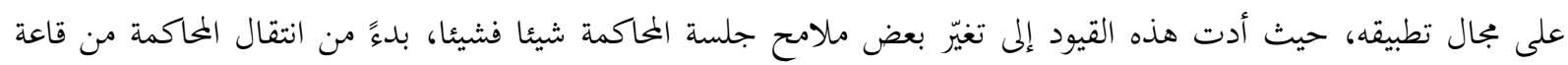
المحكمة إلى مكتب القاضي، إلى غاية الوصول بالمحاكمة خارج أسوار المحكمة عن طريق تكنولوجيات الاتصال والمعلومات.

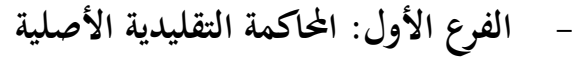

ترتكز المحاكمة التقليدية على طقوس أصبحت اليوم بنظر البعض عتيقة وذات نتائج عكسية، فهناك من يرى ضرورة تجنبها

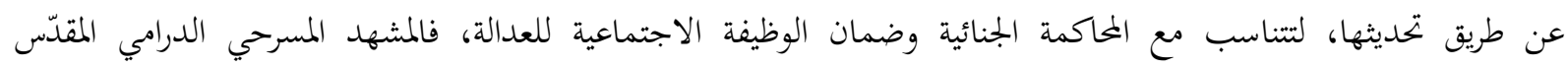

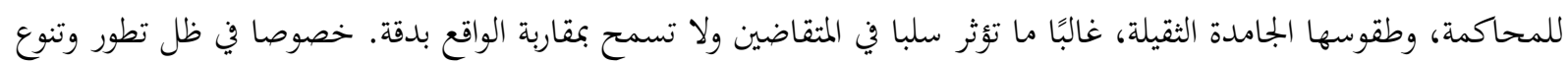
الإجرام واتساع رقعته وعبوره للأوطان، مما يستدعي تنسيقا وتواصلا سريعا بين العديد من الجهات القضائية بما يوفر فعالية ونجاعة

\section{- - الفرع الثاني: الانتقال التدريجي من قاعة الطحكمة إلى مكتب القاضي}

يقول أنطوان غاربون Antoine Garapon: " تدريجياً انتقل مركز الثقل في العدالة من قاعة المحكمة إلى مكتب

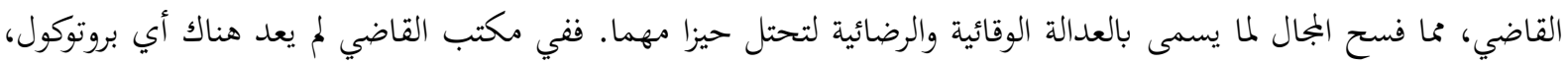

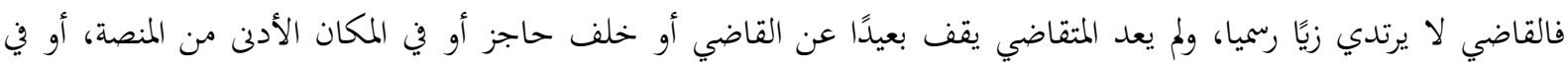

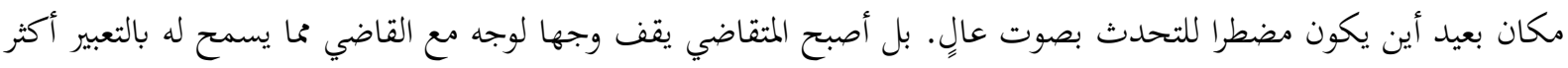

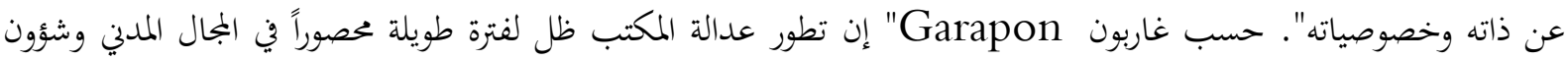

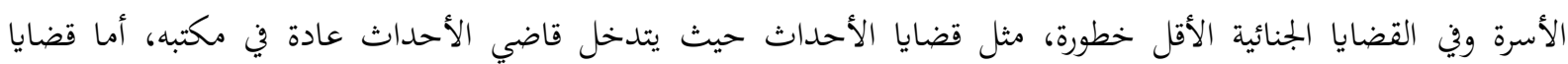

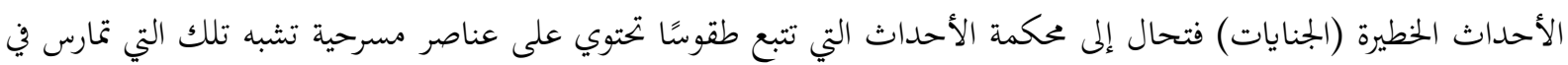
مكمة جنايات البالغين." (Antoine Garapon,1997)

\section{أولا: التحول من العدالة القهرية إلى العدالة الرضائية}

صاحب تطور الدولة وإسرافها في التجريم تضخما تشريعيا في المجال الجنائي، أدى إلى ما يعرف بأزمة العدالة الجنائية،

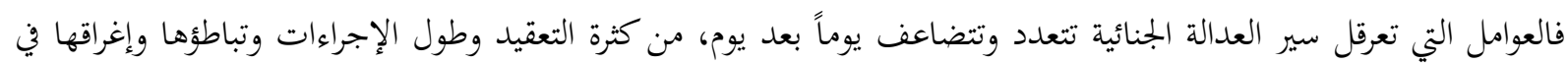


الشكليات، مما أدى بالسياسة الجنائية الحديثة مواجهةً لهذه الأزمة، إلى معاصرة بدائل العقوبة مع بدائل الدعوى الجنائية. وكان

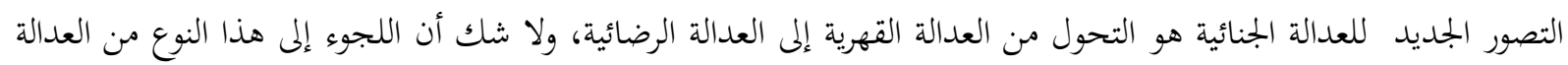

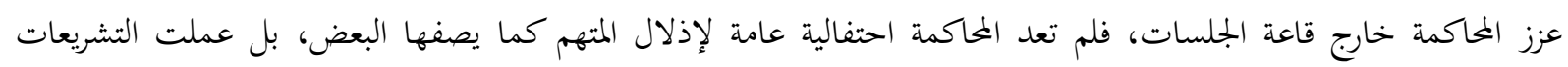

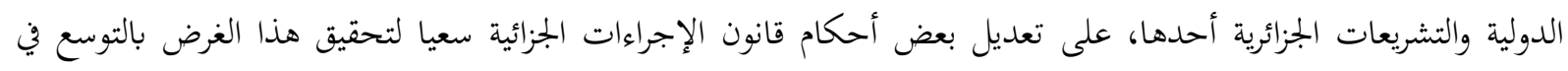

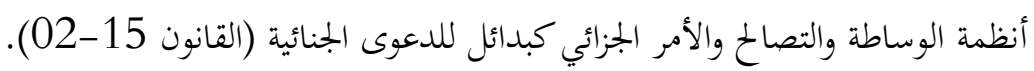

ثانيا: الانتقال إلى المكمة الالكترونية

إن الانتقال إلى المحكمة الالكترونية كان عبر تكنولوجيا المعلومات والاتصالات، بانتقال مرفق العدالة من الشكل التقليدي

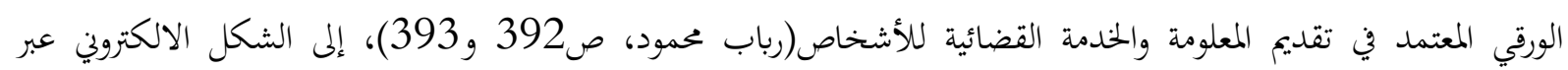
الانترنت، عن طريق ربط المحاكم القضائية كلها ضمن دائرة الكترونية واحدة بعد حوسبة عمل كل محكمة قضائية على حدىى،

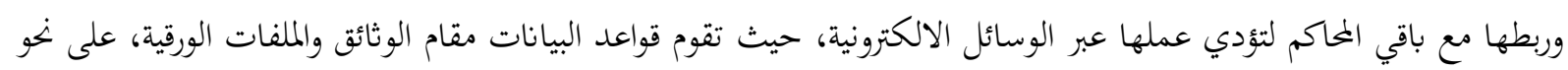

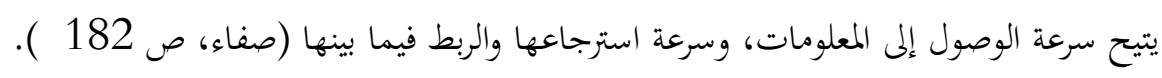
ويمكن أن تتخذ أشكالًا عديدة كالتوقيع الإلكتروني، والاتصال الإلكتروني بين المهنيين القانونيين، وكذلك رسائل البريد

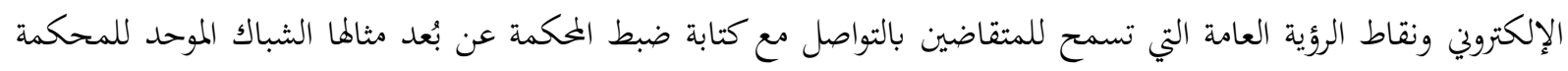

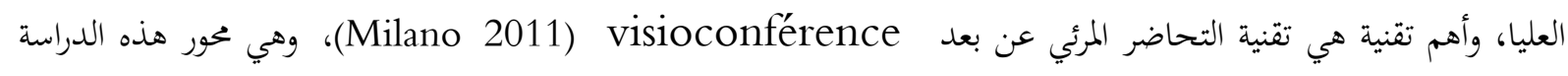

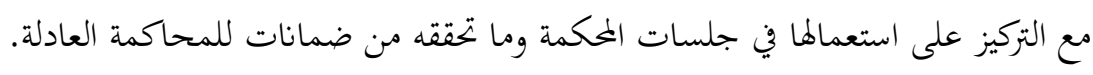
المطلب الثاني: التحاضر المرئي عن بعد تعريفه وأساسه القانوني لقد أصبح استخدام تكنولوجيا المعلومات والاتصالات في المسائل الإجرائية ضرورة حتمية في السنوات الأخيرة باعتراف

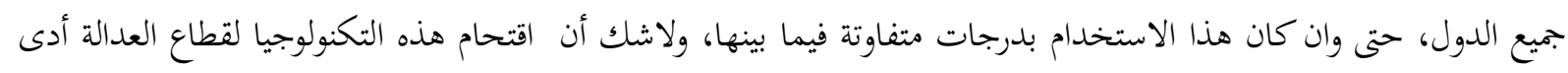
إلى عدد من التعديلات في أساليب عمل القاضي، وكذلك في حقوق أطراف الدعوى، على رأسها الحق في محاكمة عادلة وما يتطلبه من مفترضات.

\section{Visioconférence الفرع الأول: تعريف تقنية التحاضر المرئي -}

تُعرف تقنية التحاضر المرئي بأها عبارة عن: "اتصال سمعي مرئي يجري في وقت واحد، بين أطراف متفاعلة معاً في مواقع

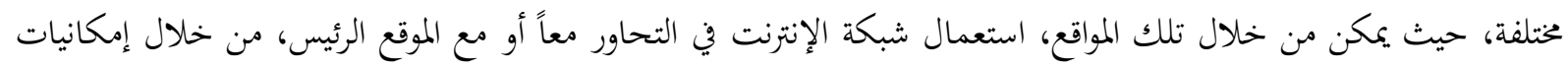

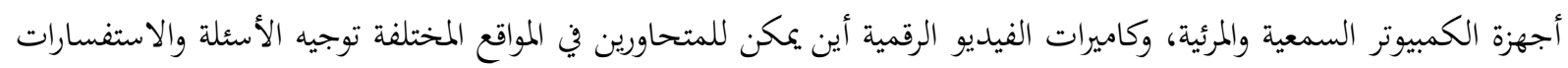

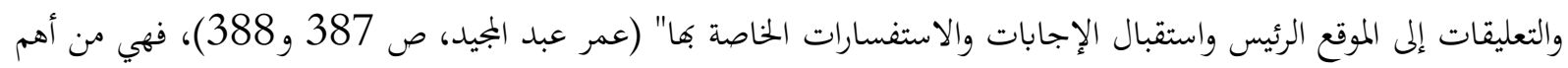

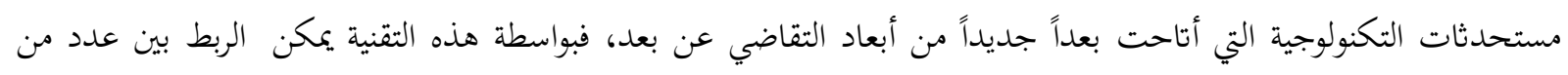
الأشخاص متواجدين في أماكن مختلفة وتفصل بينهم مسافات شاسعة، كأن تكون هيئة الحكم في مقر الجهة القضائية بعلية، فيما يتم

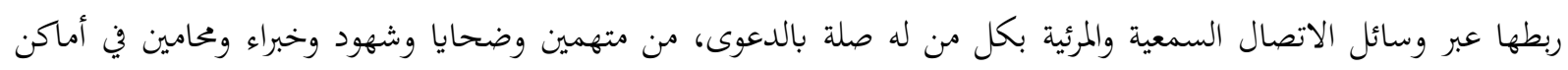

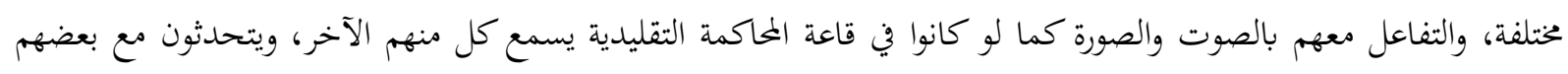

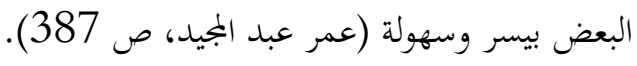




\section{- - الفرع الثاني: الأساس القانوبي لتقنية التحاضر المرئي عن بعد}

ترتبط فكرة التقاضي أو المحاكمة عن بعد عبر تقنية التحاضر المرئي في الجزائر بالتقاضي الالكتروني و التي تحد أساسها

$$
\text { القانوين في الاتفاقيات الدولية، وبعض القوانين الداخلية. }
$$

\section{أولا: تقنية التحاضر المرئي عن بعد في الاتفاقيات الدولية}

نصت المادة 69:2 من نظام روما الأساسي (جويلية 1998) على استخدام التحاضر المرئي عن بعد في قطاع العدالة بقوها:

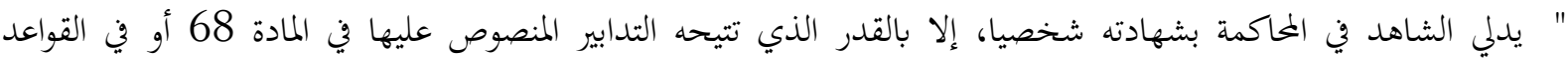

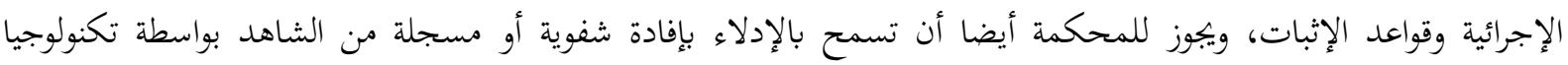

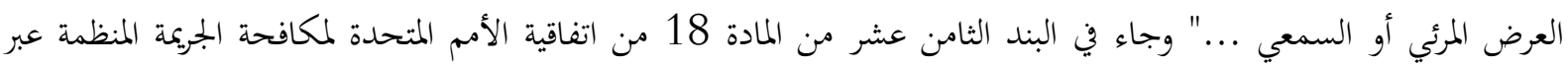

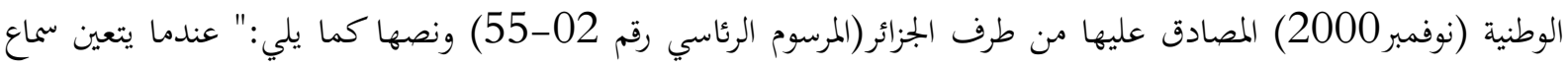
شخص موجود في إقليم دولة طرف، بصفة شاهد أو خبير أمام السلطات القضائية لدولة طرف أخرى، ويكون ذلك ممكنا ومتفقا

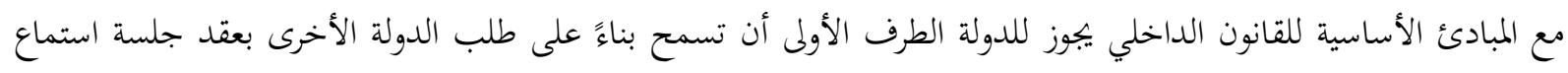

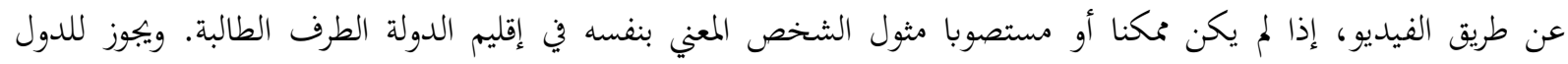

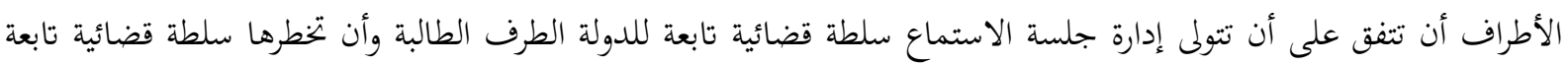
للدولة الطرف متلقية الطلب." أيضا ورد في المادة 36:3: ب من الاتفاقية العربية لمكافحة الجريمة المنظمة عبر الحمدود الوطنية لسنة (2010) النص على: " إتاحة الإدلاء بالشهادة على نخو يكفل سلامة الخبراء والضحايا، ويجوز استخدام التقنيات الحديثة في

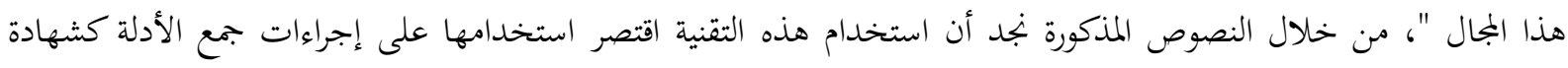
الشهود والخبراء الذين يتعذر حضورهم شخصيا.

\section{ثانيا: تقنية التحاضر المرئي عن بعد في القانون الداخلي}

إن من أهم القوانين التي شرعت استخدام هذه التقنية في الجزائر، القانون رقم 15-03 المتعلق بعصرنة العدالة(عمد

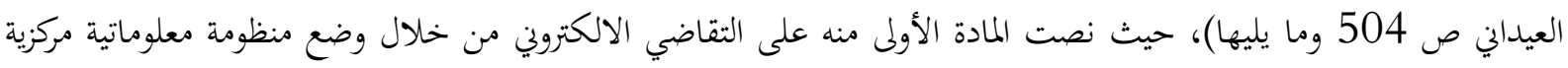
لوزارة العدل، واستخدام تقنية المحادثة المرئية عن بعد في الإجراءات القضائية، وإرسال الوثائق والمحرات القضائية بطريقة الكترونية، حيث نصت المادة 14 على أنه: " إذا استدعى بُعد المسافة أو تَطلب ذلك حسن سير العن العدالة يمكن استجواب وسماع الأطراف

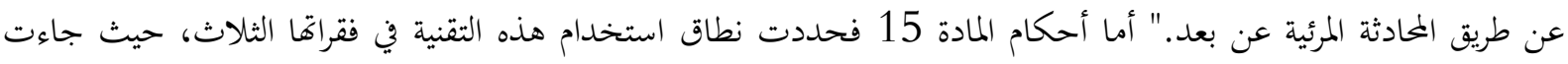

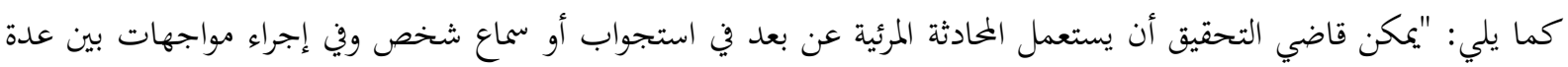

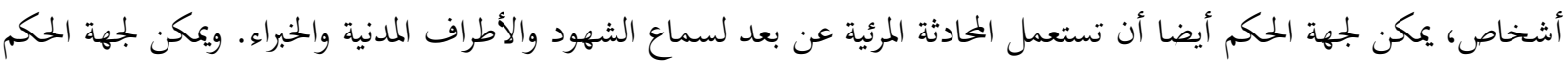

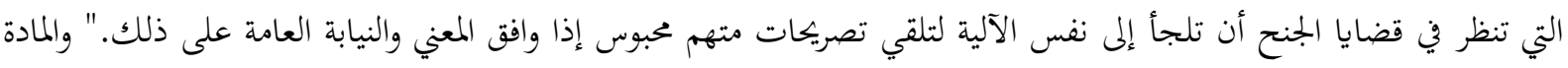
16 التي حددت مكان إجراء التقاضي الالكتروني بنصها: "يتم الاستجواب أو السماع أو المواجهة باستعمال آلية المحادثة المرئية

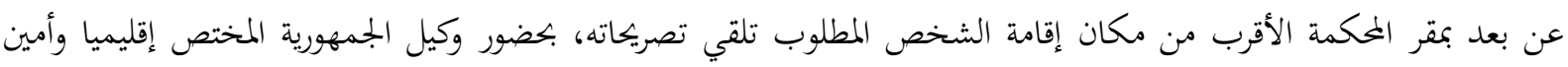

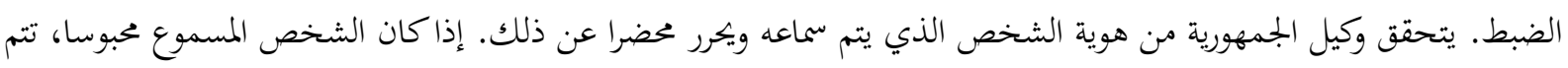

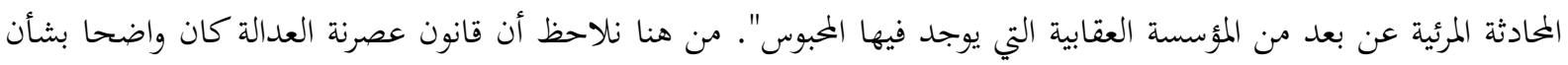
استخدام هذه التقنية في مرحلة المحاكمة.

ونص المشرع لأول مرة في قانون الإجراءات الجزائية على استخدام هذه التقنية بموجب الأمر رقم 15-02، المعدل والمتمم

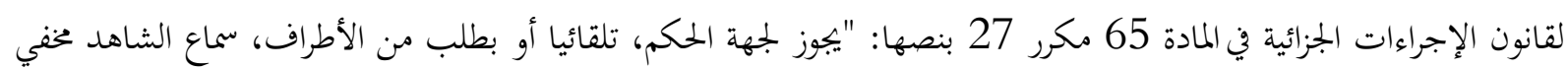


الهوية عن طريق وضع وسائل تقنية تسمح بكتمان هويته، بما في ذلك السماع عن طريق المحادثة المرئية عن بعد واستعمال

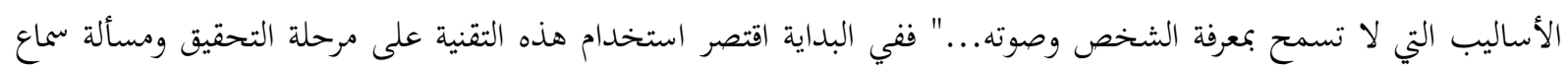

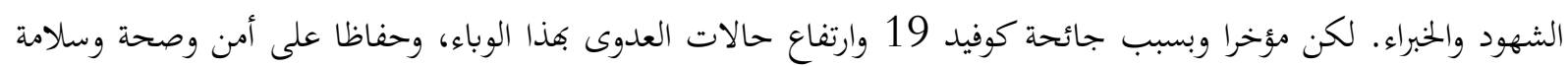

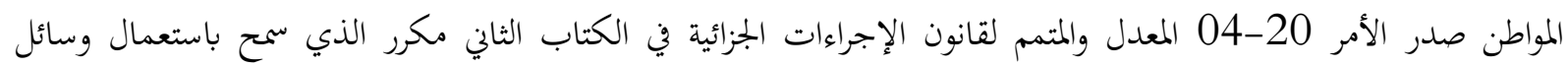

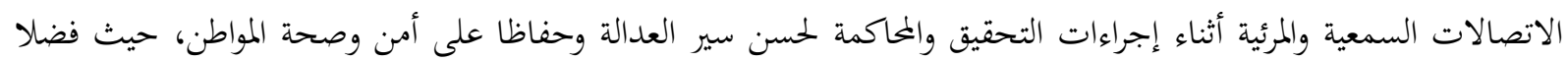

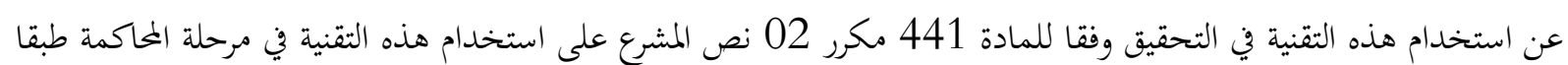

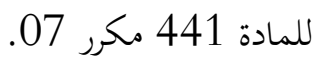
ثالثا: تقنية التحاضر المرئي عن بعد غيرت من ملامح جلسة الحماكمة

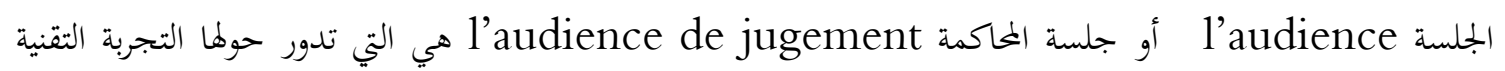

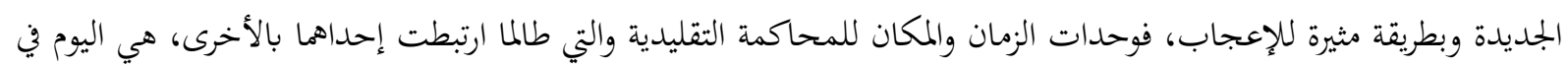

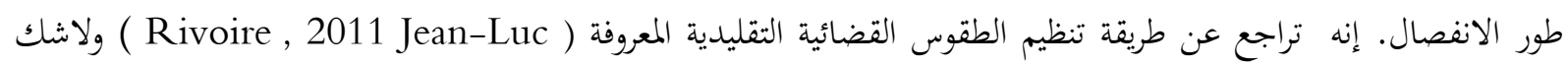

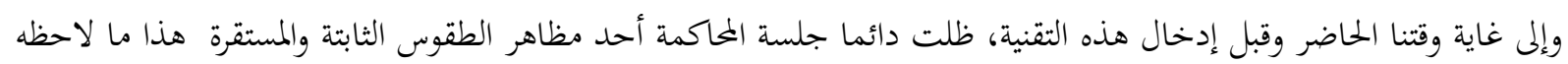

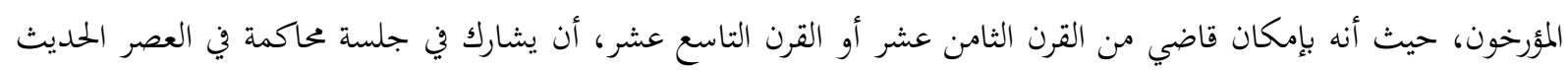

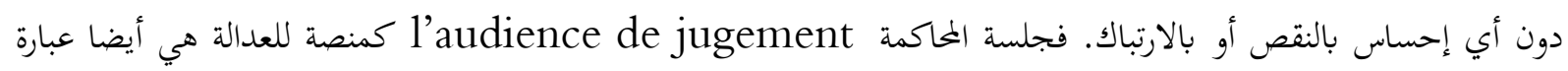

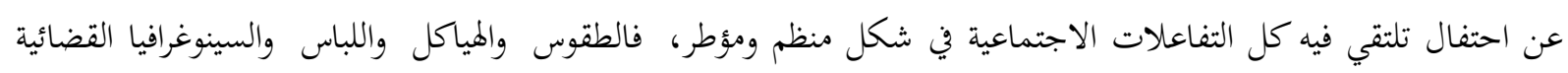

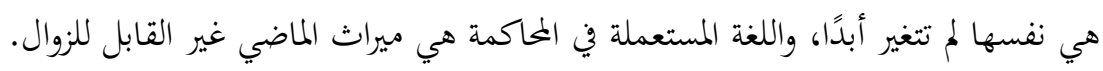

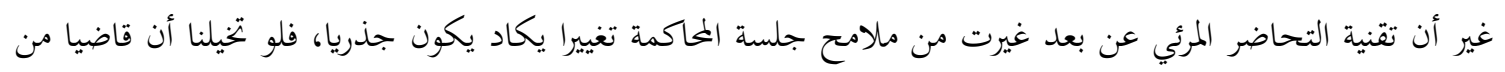

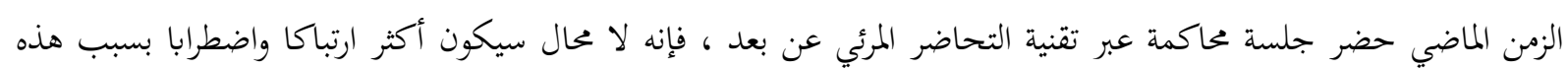

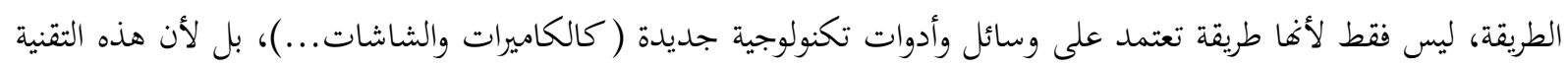

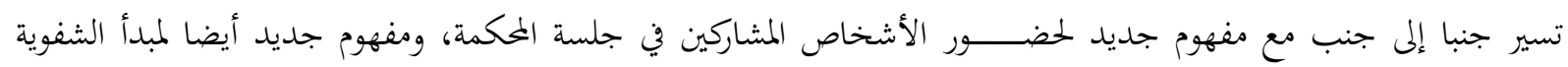
والمواجهــــــــ (Licoppe Dumoulin, p13) باعتبارهما من المبادئ الأساسية للمحاكمة العادلة. 


\section{المبحث الثاني: تأثير تقنية التحاضر المرئي عن بعد على الحق في محاكمة عادلة}

يعتبر الحق في محاكمة عادلة من أهم حقوق الإنسان، بما يوفره من حماية لحقوق الإنسان الأخرى. وحتى تكون المحاكمة

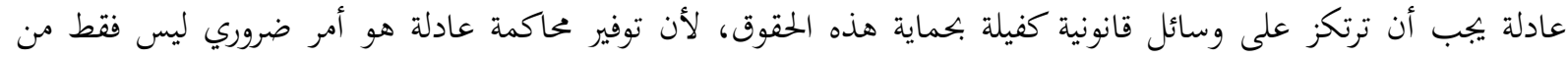
منظور حماية حقوق المتهمين أو الضحايا، لكن لضمان حسن سير العدالة أيضا، وإذا كانت المحاكمة العادلة تتعلق بكافة المراحل الإجرائية للدعوى، فإننا في دراستنا هذه نسلط الضوء على المرحلة النهائية وهي مرحلة المحاكمة وما يرتبط بها من ضمانات إنهات إجرائية كانت أو موضوعية تكفل الحق في محاكمة عادلة.

المطلب الأول: مخاطر التحاضر المرئي عن بعد على مبادئ المحاكمة العادلة إن أهم المبادئ التي نود التركيز عليها هي تلك التي ترتبط ارتباطا مباشرا بمرحلة المحاكمة، مثل مبدأ الحضورية والشفوية

\section{- الفرع الأول: الحق في الحضور الشخصي لجلسة المحاكمة(مبدأ الحضورية)}

تكون إجراءات التحقيق النهائي حضورية بالنسبة لخصوم الدعوى، فالقاضي الجنائي يبني عقيدته بحرية كاملة بناءً على ما

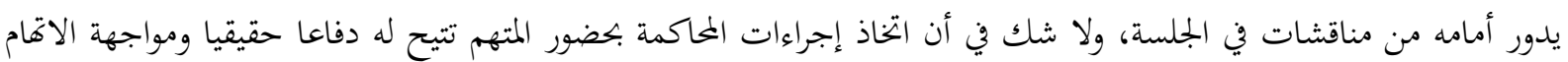

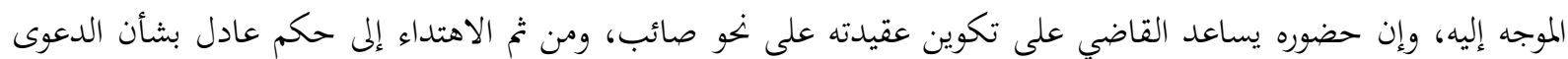

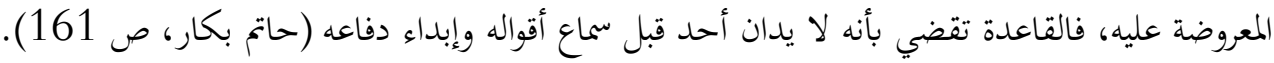
أولا: ضرورة الحضور الشخصي كضمانة في التحقيق النهائي:

إن الحضور الشخصي ضمانة أكيدة وضروري أيضا لمبدأ شفوية المرافعة حيث يُمَكِّنُ جهة الحكم والخصوم من مناقشة الأدلة المقدمة، فلا يكفي صحة الدليل لاقتناع المحكمة به، بل لابد من أن يكون هذا الدليل قد تمت مناقشته في الجلسة المادة

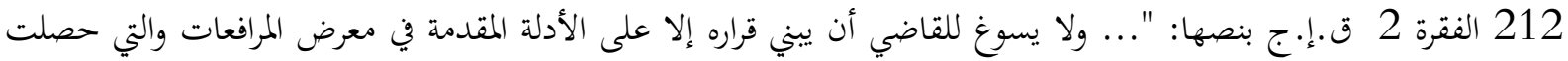
المناقشة فيها حضوريا أمامه "، ويقتضي هذا المبدأ تمكين الخصوم من حضور الجلسة وذلك بإعلامهم بموعدها قبل انعقادها،

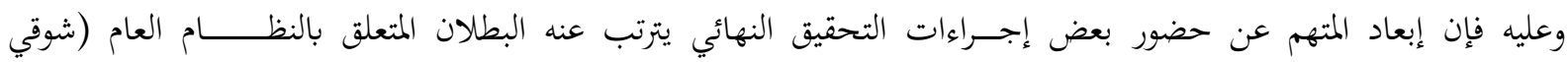

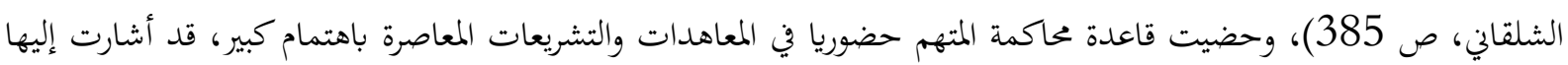

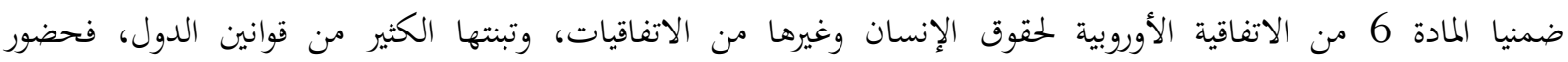

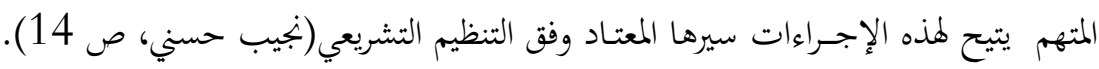
ثانيا: موقف المشرع من مبدأ الحضورية عبر تقنية التحاضر المرئي عن بعد

بعد أن كانت هذه التقنية مقتصرة على مرحلة التحقيق لأجل الاستجواب وسماع الشهود، انتشرت بشكل ملفت للانتباه

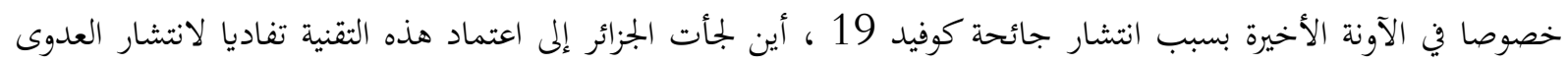
وتسييرا حسنا لمرفق العدالة الذي عرف تدبدبا كبيرا بسبب الحجر الصحي، حيث أدخل المشرع تعديلات على قانون الإجراءات

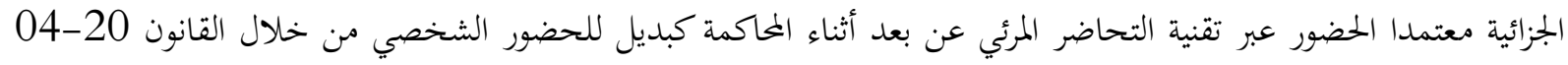

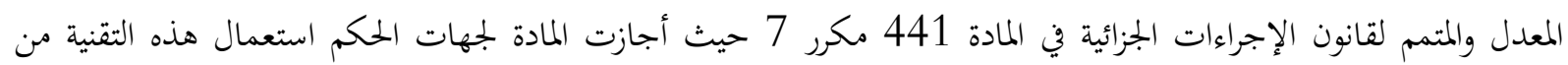

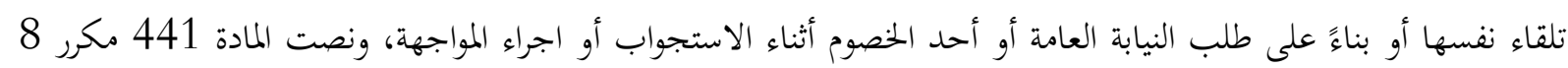

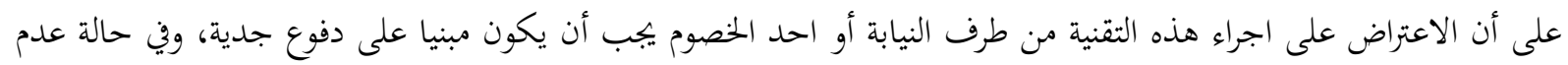

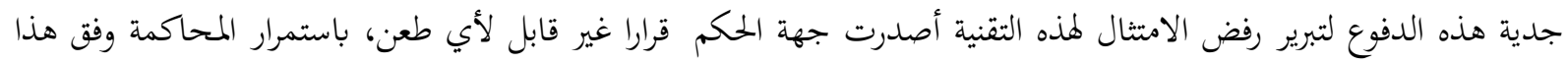


الإجراء وفي هذه الحالة يمق للدفاع الحضور رفقة موكله بككان سماعه أو أمام جهة الحكم المختصة. ونصت المادة 441 مكرر 9 المان

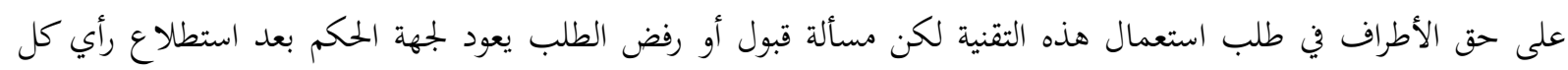

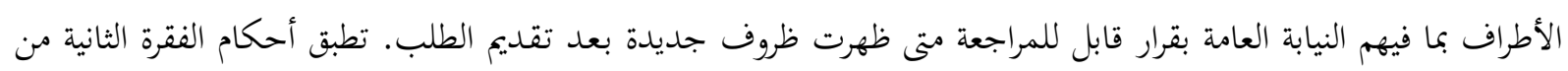

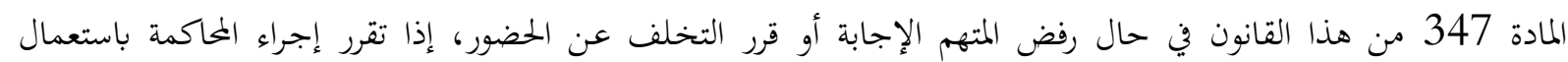

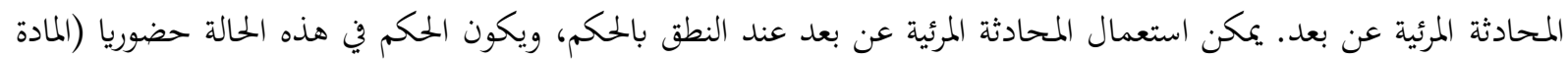

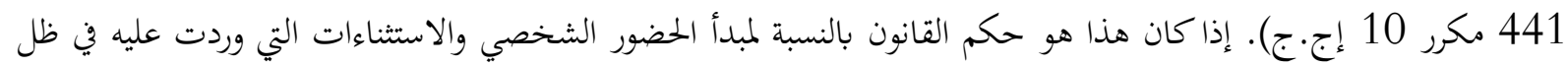

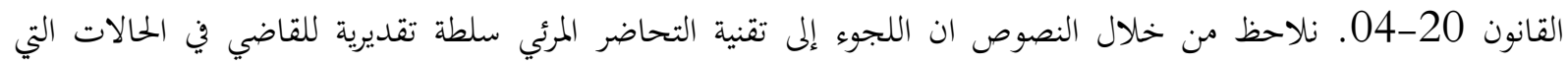

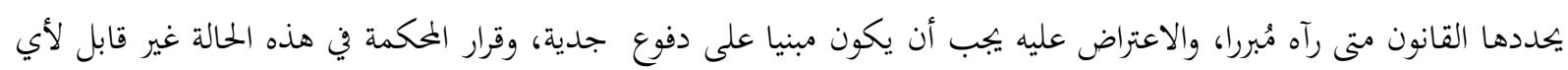

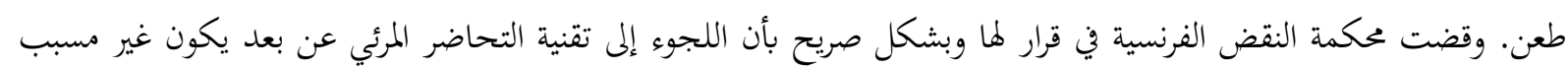

.(cass. Crim., 2 mars 2011)

ثالثا: موقف القضاء من مبدأ الحضورية عبر تقنية التحاضر المرئي عن بعد لقد ثار جدل كبير بخصوص الحضور عبر تقنية التحاضر المرئي عن بعد وأثره على قاعدة الحضور الشخصي كضمانة

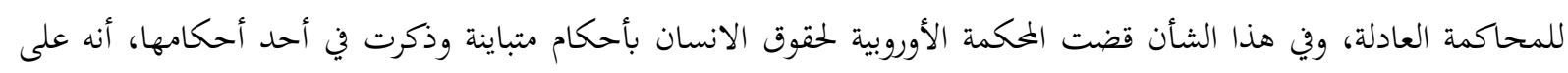

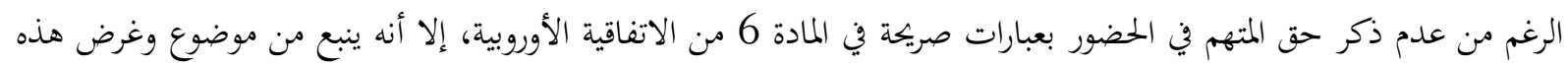

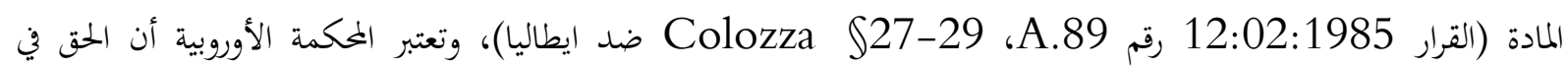

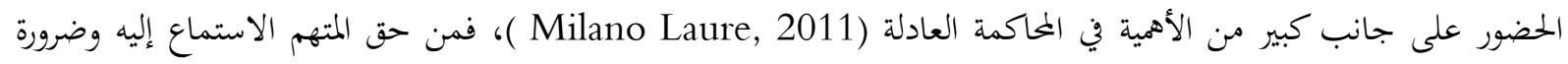

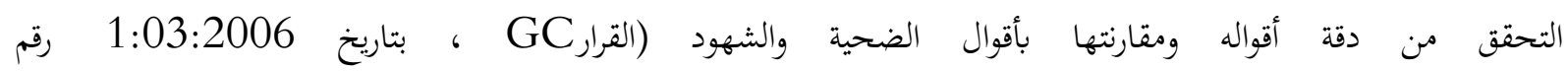

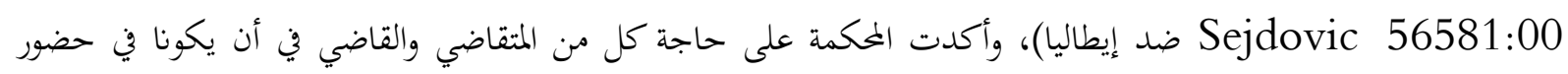

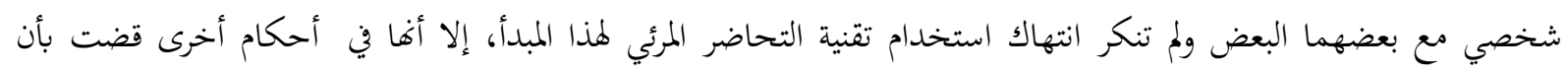

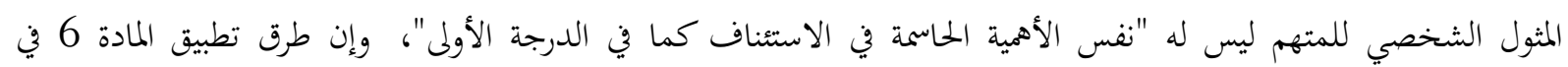

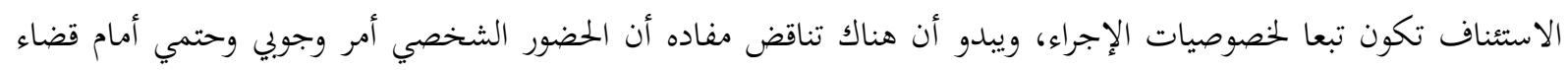

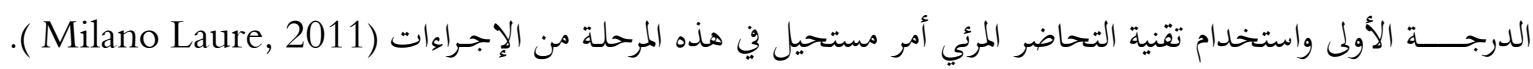

- الفرع الثاني: تأثير تقنية التحاضر المرئي عن بعد على حق الخصوم في تبادل الحوار شفاهة( مبدأ الشفوية)

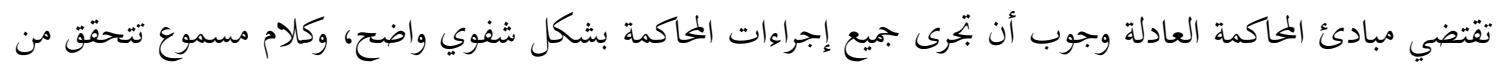

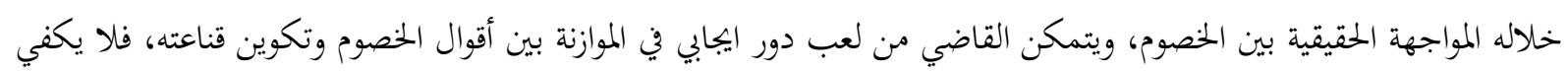

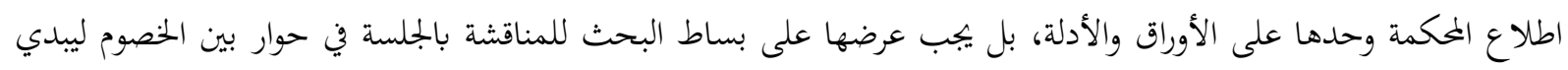

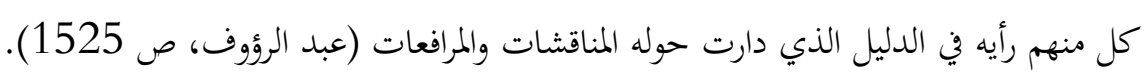

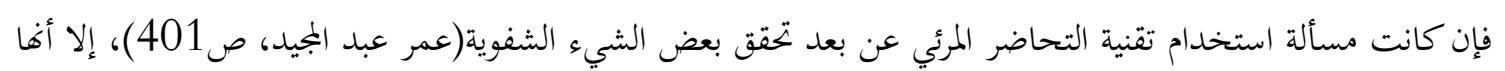

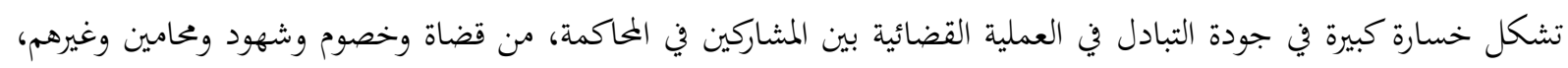

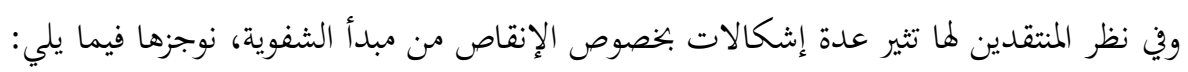

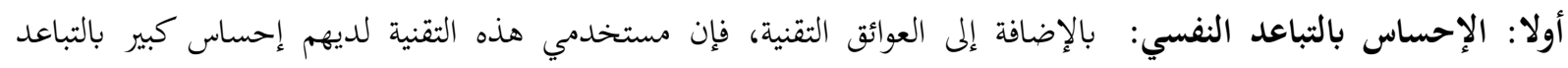

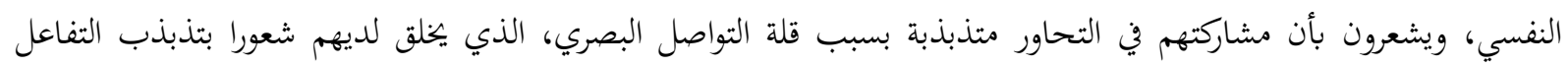

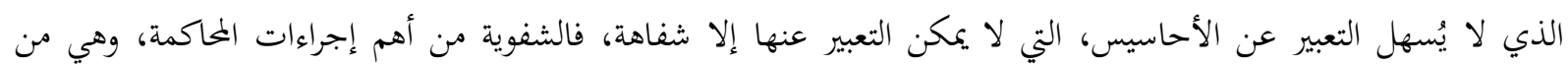


مظاهر المواجهة بين الخصوم، وضمانة أساسية من ضمانات المحاكمة العادلة ( Jean-Luc Rivoire , 2011 ) واستعمال هذه التقنية قد يجعل الحوار لا يتحقق معه مبدأ الشفوية بالمفهوم التقليدي السابق، حيث يجتمع كل الأطراف في مكان واحد هو جلسة المحاكمة، وترتبط الشفوية بالوجاهية التي يجب احترامها من حيث المبدأ في إعطاء الكلمة لجميع الخصوم على قدم المساواة. ثانيا: تقنية التحاضر المرئي عن بعد تقوض جودة الاستماع: لا شك أن استخدام هذه التقنية يقوض عمليًا جودة استماع

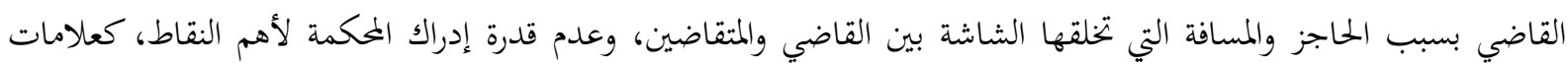

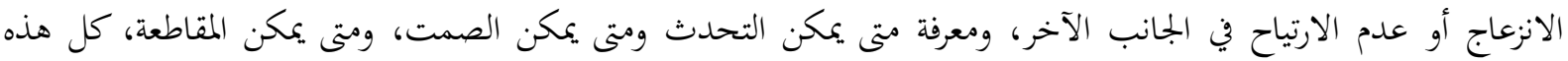
البديهيات الضرورية لممارسة حق الدفاع بشكل كامل تختنفي أثناء المرافعة من خلال تقنية التحاضر المرئي عن بعد، بالإضافة إلى بلى الأعطال الفنية في الاتصال، مثل انقطاع الصورة أو الصوت، حيث يصعب على الخصم والشخص المترافع الإحساس بأن القضية قد نوقشت بطريقة وجاهية. ويزداد الإحساس بالإحباط أكثر لأن النيابة العامة حاضرة في قاعة المحكمة وتستفيد من الاستماع والمعلومة التي لا تتناسب جودةا مع تلك المقدمة إلى المتقاضي في الطرف الآخر، وفي هذا السياق قضت محكمة النقض المصرية بأنه:" في الحالة التي تتعذر فيها المواجهة وفقا للمفهوم التقليدي ويكون سماع الأقوال الشفوية غير ممكنا، فإن تطبيق مبدأ الشفوية عبر تقنية التحاضر المرئي عن بعد من شاشة إلى أخرى تكون ملائمة وعادلة وأكثر قدرة على أداء وظيفتها من التمسك بلك بالمفهوم

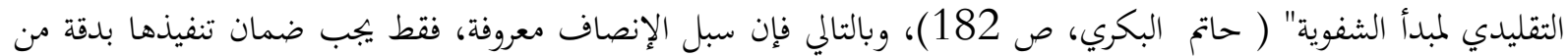
خلال بنية تحتية تقنية ذات جودة عالية وتسيير فعال، بالإضافة إلى اهتمام القضاة المتزايد ووعيهم الدائم بالحفاظ على تكافؤ مبدأ التساوي في الأسلحة liégalité des armes بينة الاتحام والدفاع.

\section{- الفرع الثالث: الحق في علنية المحاكمة عبر تقنية التحاضر المرئي عن بعد (مبدأ العلنية)}

العنية ضمانة هامة لتحقيق المحاكمة العادلة ضد أي عدالة سرية، فهي الرقيب على عدالة الإجراءات، ومن أبرز مظاهرها

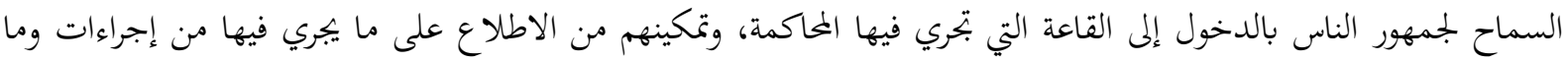

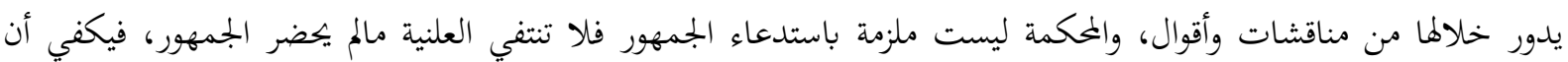
المحكمة أتاحت له ذلك ما دامت أبواب القاعة مفتوحة. أولا: ضرورة اجراء المحاكمة بصفة علنية: وتوصف جلسة المحاكمة العلنية l'audience public بأها أحد النقاط الأساسية

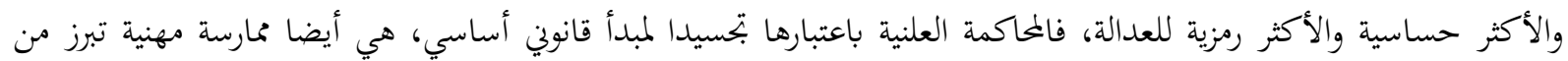
خلالها خبرة وأهلية الفاعلين في الساحة القضائية من محامين وقضاة وكتاب ضبط وخبراء، فهي عبارة عن عرض مسرحي علني للعملية القضائية، وتقليديا جلسة المحاكمة تعتمد على احتفالية شعبية أساسها حضور ومشاركة الأطراف في هذه الاحتفالية و طقوس تكون أساسية في القضايا الجنائية حيث تكون النيابة العامة، المتهمين، الضحايا، القضاة والجمهور مجتمعين شخصيا في في نفس المكان وهو قاعة الجلسات (Antoine Garapon, 2001 ). فالعنية هي النتيجة الطبيعية للمحاكمة العادلة، فعندما تجرى المرافعات على شبكة اتصالات وليس في قاعة الجلسات، فإن مبدأ علنية المرافعات يصبح محل استفهام. ثانيا: العلنية ليست قاعدة مطلقة: نعلم جيدا أن مبدأ علنية جلسة المحاكمة ليس مطلقًا فله عدة استثناءات في حالات معينة معروفة قانونا، ولقد لاحظنا أخيراكيف أصبحت قاعات المحاكم شبه مهجورة بسبب إجراءات الحجر الصحي التي تبعت جائحة

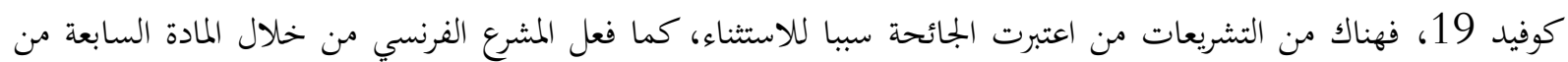

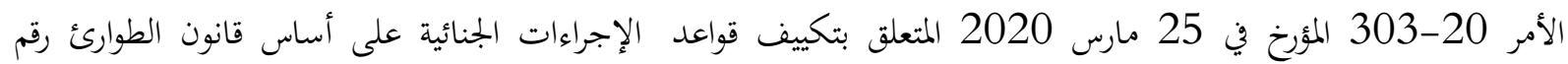

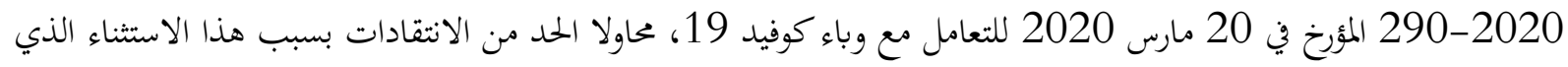


يحد من العلنية وذلك من خلال النص صراحة على إمكانية السماح بحضور الصحفيين الجلسات حتى في الحالة التي يأمر فيها

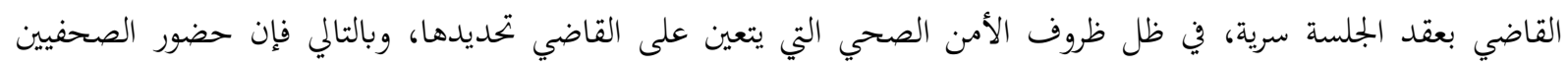

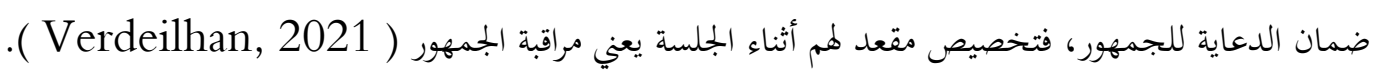
إن علانية المحاكمة وفقاً لتقنية التحاضر المرئي عن بعد لا تحقق الفائدة المرجوة المطلوبة في إجراءات التقاضي كما هو الحال عند

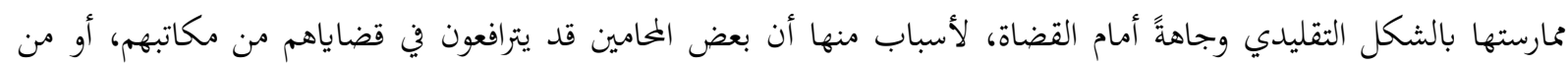

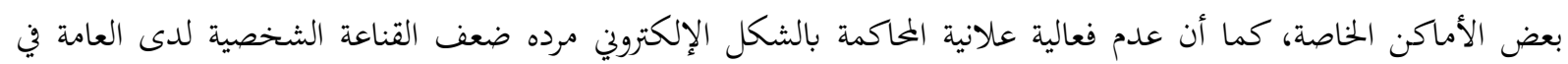
التقاضي الالكتروني.

في الحالة التي لم يكن من الممكن فيها أن تُعقد الجلسة بحضور الجمهور (كفرضية محاكمة متهم موجود في السجن) فمن

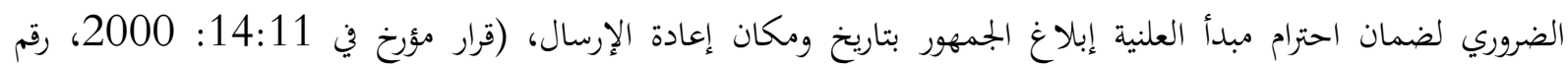
Riepan 35115:97

المطلب الثاني: مخاطر تقنية التحاضر المرئي على بعض الحقوق الأخرى نلخص هذه الحقوق في بعضها والتي لها أهميتها كالحق في الوصول إلى القاضي والحق في المشورة القانونية وإعداد الدفاع. - الفرع الأول: الحق في الوصول إلى القاضي - المي

يطرح المختصون عدة تساؤلات حول المحاكمة عبر تقنية التحاضر المرئي بعد، وما إذاكانت تتيح للمتهم الوصول الملموس والفعال

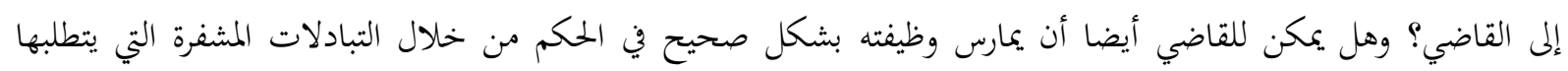

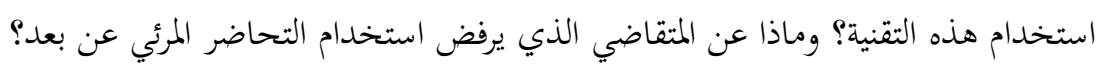

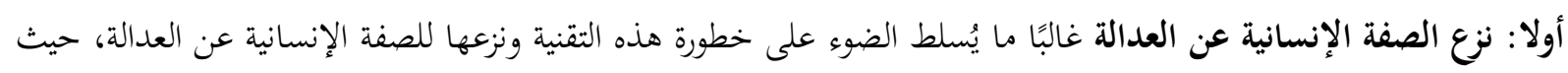

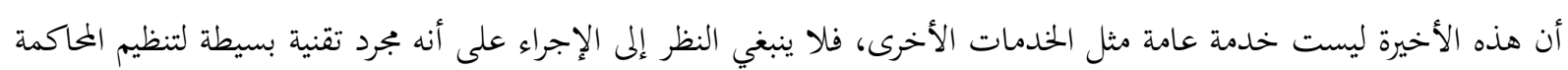

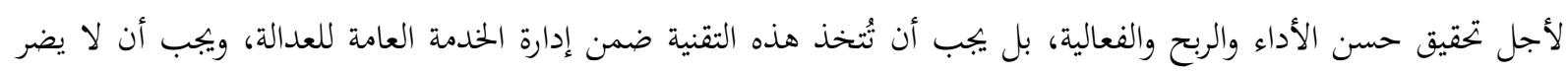

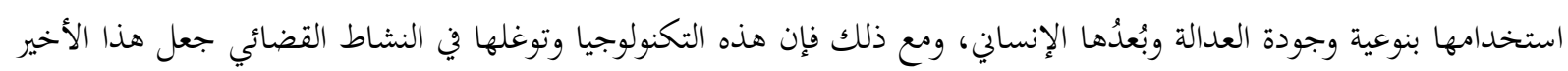

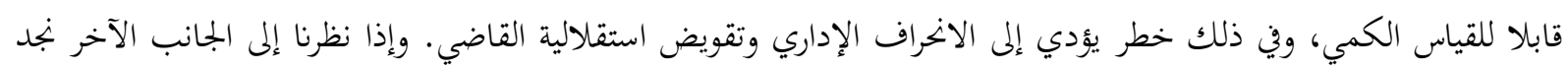

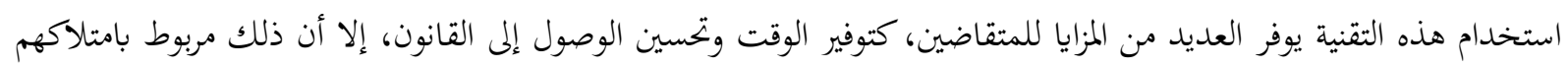

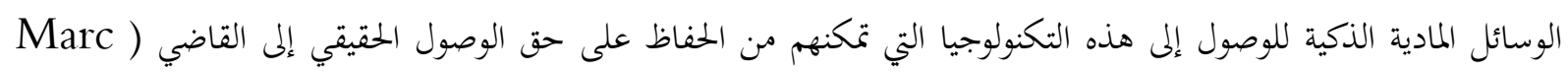

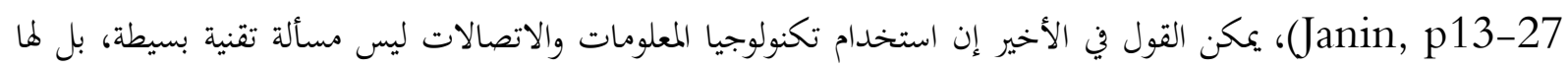
تأثير حقيقي على مهمة القضاء وعلى الحقوق الإجرائية للمتقاضين خصوصا في البلدان التي تفتقد لوسائلها. ولقد أصدرت المحكمة الأوروبية لحقوق الإنسان عددًا من الأحكام المتعلقة بالتحاضر المرئي رصدت من خلالها بعض الانتهاكات

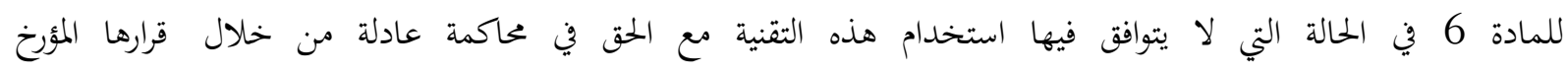
في 21272:03 02:11:2011 رقم ثانيا: رفض المتقاضين للمحاكمة عبر تقنية التحاضر المرئي عن بعد قضى المجلس الدستوري الفرنسي في هذا الشأن في قرارين له بعدم دستورية الفقرة الأولى من المادة 5 من الأمر رقم 303 لسنة

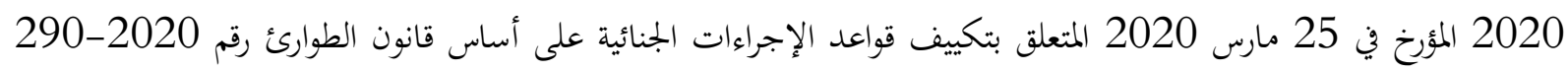

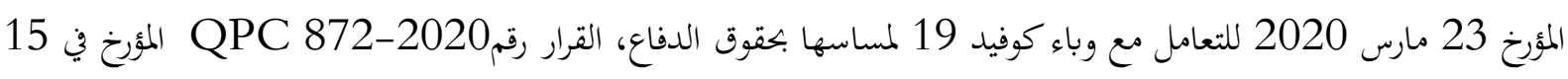


جانفي 2021، والقرار رقم 2021-QPC 919 المؤرخ في 4 جوان 2021، حيث أن المشرع في المادة 5 السالفة الذكر

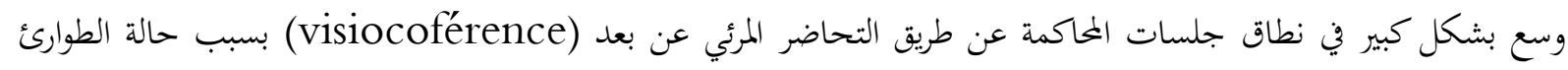

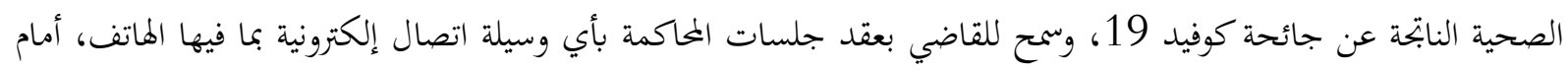

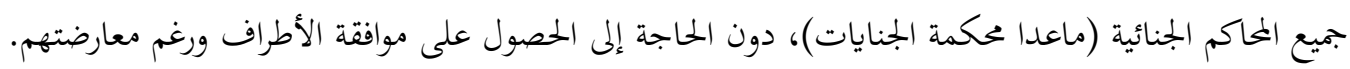
- الفرع الثاني: ضمان الممارسة الفعلية للحق في الاستعانة بمحام

أقر المشرع الجزائري شأنه شأن كل التشريعات حقوق الدفاع بنص الدستور المادة 169 ونصوص القوانين الأخرى، الماني،

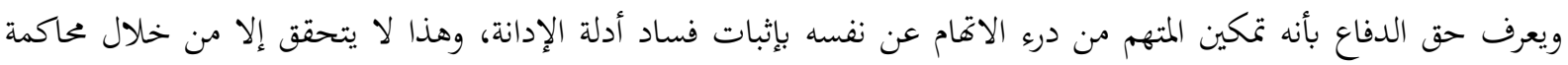

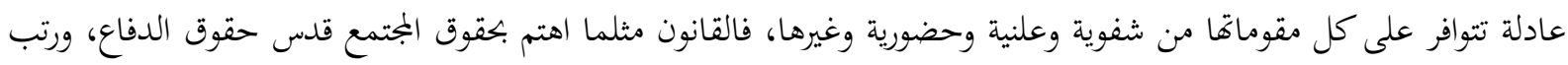

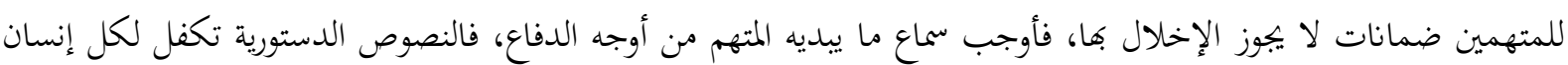

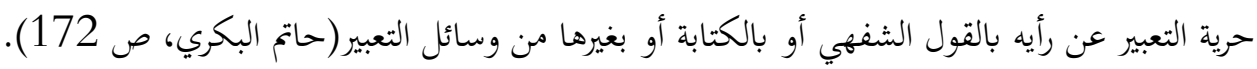

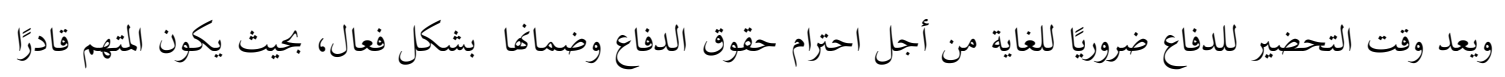

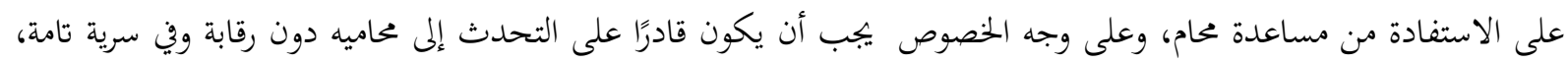

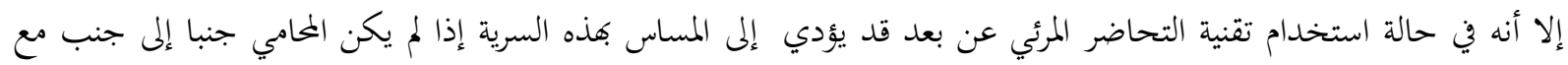

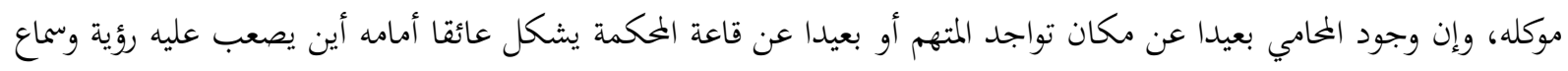

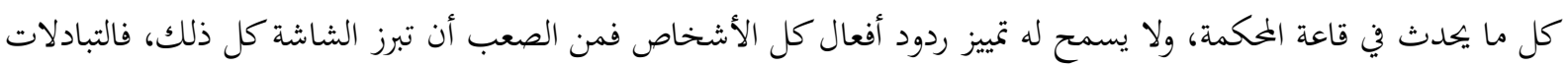

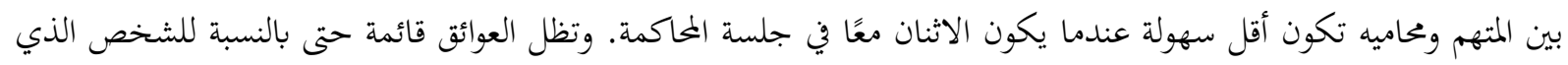

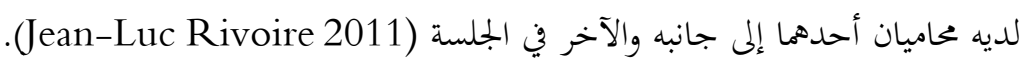

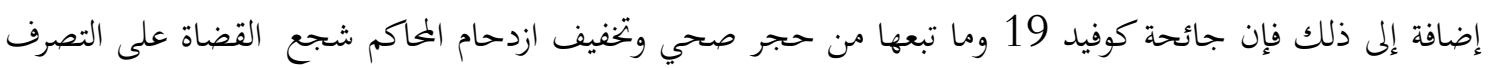

$$
\text { بسرعة، طبعا مع وجوب الاحترام اللازم لوقت التحضير للدفاع. }
$$




\section{المبحث الثالث: تطابق تقنية التحاضر المرئي عن بعد مع الحقى في محاكمة عادلة}

بالنسبة لاستخدام هذه التقنية ومدى تطابقه من عدمه مع الحق في المحاكمة العادلة، فإن المحكمة الأوروبية لحقوق الإنسان قضت في هذا الشأن بعدة أحكام مختلفة نستعرضها ونستعرض رأي المختصين في هذا الشأن فيما يلي: المطلب الأول: التحاضر المرئي يسعى لتحقيق هدف مشروع تعتبر المحكمة الأوروبية لحقوق الإنسان مشاركة المتهم في الإجراءات عن طريق تقنية التحاضر المرئي عن بعد لا يتعارض في

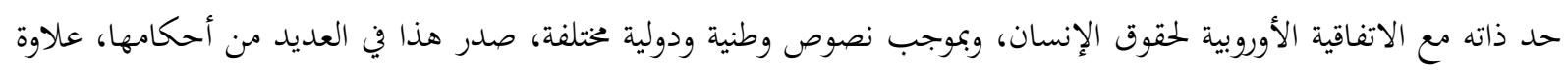

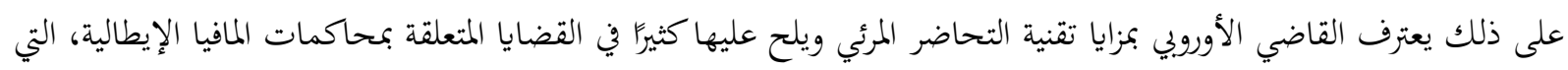

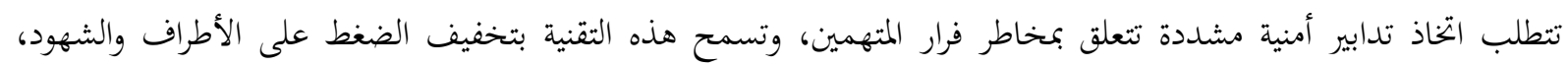

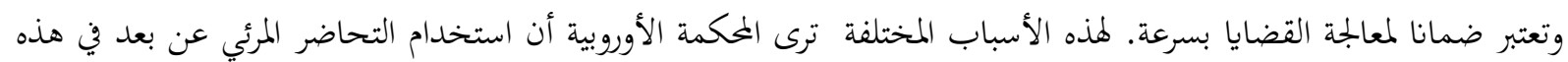

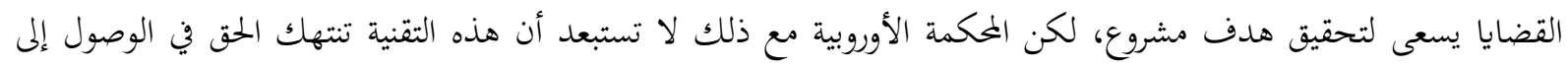

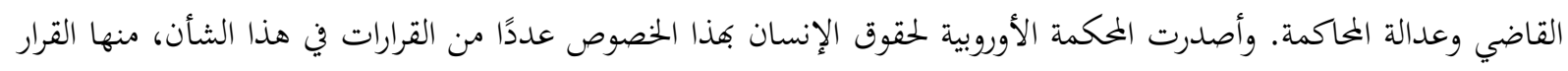

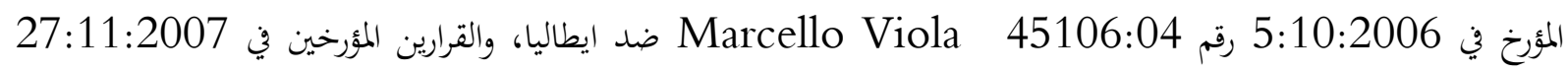

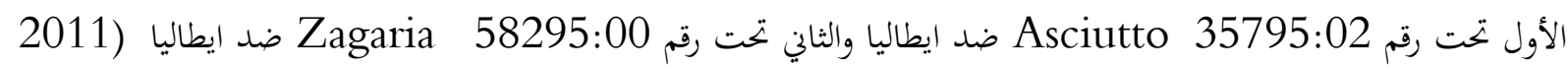

.(Milano Laure

\section{المطلب الثاني: ضرورة الإشراف على التحاضر المرئي عن بعد لضمان الحق في محاكمة عادلة.}

إن مختلف القضايا المرفوعة أمام المحكمة الأوربية، دافعت فيها الدول المدعى عليها جميعًا بأنه لا يوجد فرق جوهري بين الحضور الشخصي للمتهم ومشاركنه في الإجراءات باستخدام تقنية التحاضر المرئي عن بعد، لكن هناك من المختصين من يدعو

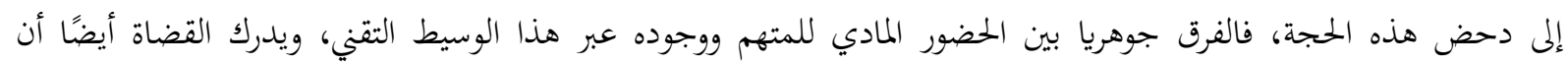

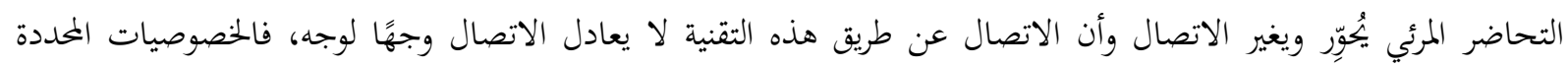

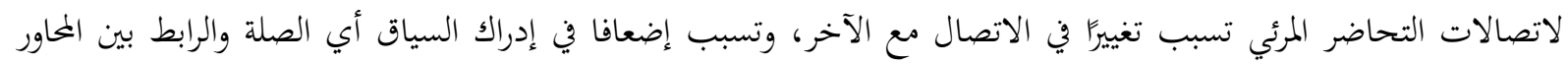

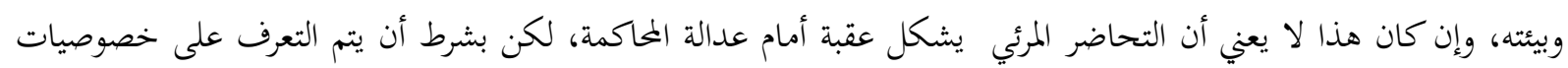

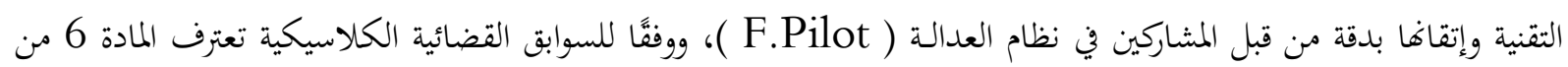

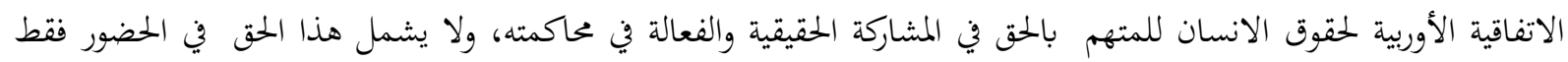

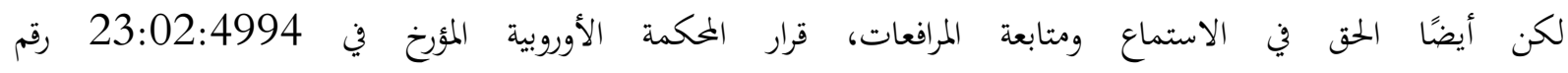
16757:90 ومع ذلك تمارس المحكمة الأوروبية رقابة حقيقية من أجل احترام عدالة المحاكمة عند استخدام التحاضر المرئي. وبحري رقابة

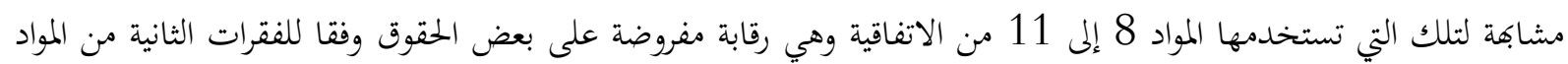
السابقة الذكر، التي تحدد قائمة بالقيود الواردة على التمتع بتلك الحقوق، ولا تحتوي المادة 6 على أسباب مقيدة المباد (باستثناء المتعلقة

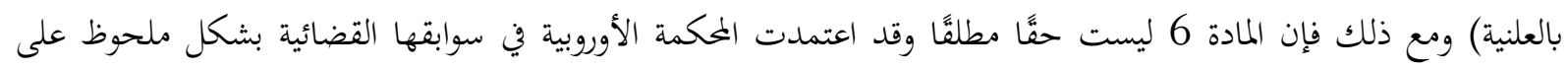
نظرية القيود الضمنية لتنظيم الحق في الوصول إلى المحكمة، من هنا يبرز أنه في قضايا التحاضر المرئي تنظر المحكمة في المادة

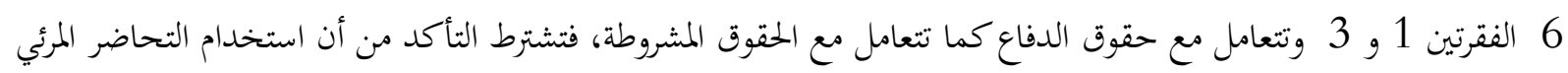
منصوص عليه في القانون وأنه يسعى لتحقيق أهداف مشروعة، حيث أن بعض النزاعات لا تصلح لأن تكون محلا لاستخدام

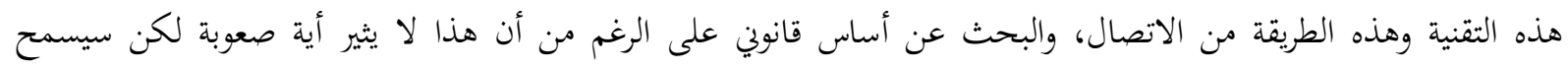


للمحكمة بالتحقق من عدم وجود استخدام مفرط لهذه التقنية، وتبقى الخطوة الأخيرة التحكم بشكل أكثر دقة فيما يتعلق بالمادة

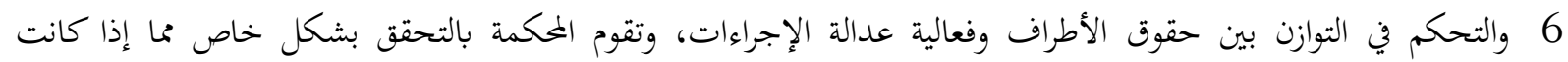

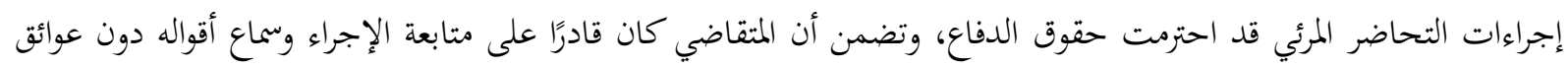

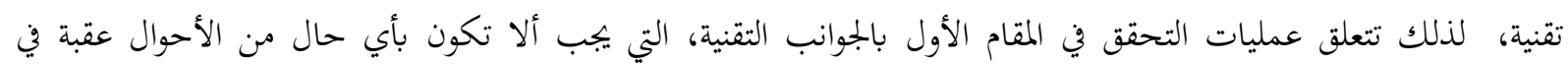
الاتصال بين المتهم والأطراف الأخرى والقاضي.

لذلك يجب على الدول توفير الموارد اللازمة للمحاكم، كما يجب عليها توقع الأعطال الفنية المختملة.

المطلب الثالث: أهمية تقنية التحاضر المرئي بالنسبة للعدالة والمتهم

توفر استخدام تقنية التحاضر المرئي في المسائل القضائية العديد من المزايا، وهذا ما يفسر لجوء العديد من الدول إلى تكثيف

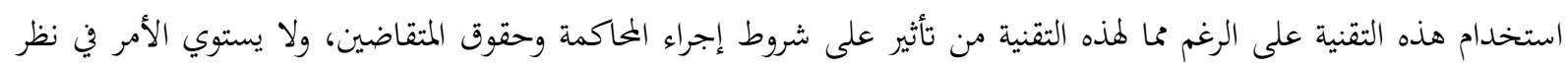

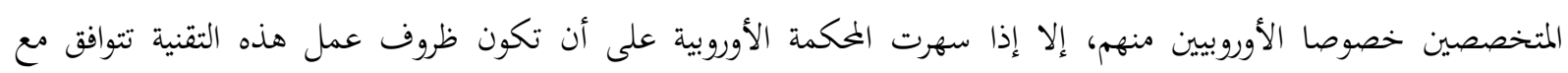
متطلبات المحاكمة العادلة، وذلك من خلال تعزيز وسيطرة مراقبتها في السنوات القادمة (Milano Laure 2011). إن استخدام تقنية التحاضر المرئي في مجال العدالة يميل اليوم ليصبح مؤسسيًا، مما يؤدي إلى ميلاد شكل جديد للإجراءات

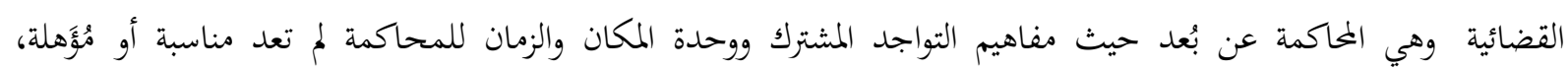

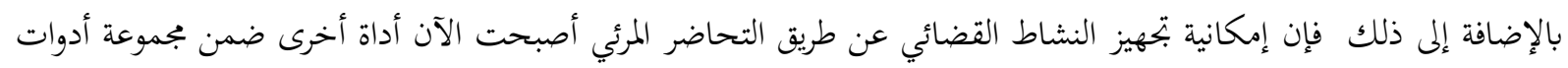
العمل العام وحل ثابت، من المرجح أن يتم استعماله على نطاق واسع لحل المشاكل العامة الجديدة مثل نقل المعتقلين.

\section{- الفرع الأول: مزايا تقنية التحاضر المرئي بالنسبة للعدالة}

تعد تقنية التحاضر المرئيe la visioconférence دون شك واحدة من أكثر الأدوات الرمزية لتكنولوجيا المعلومات

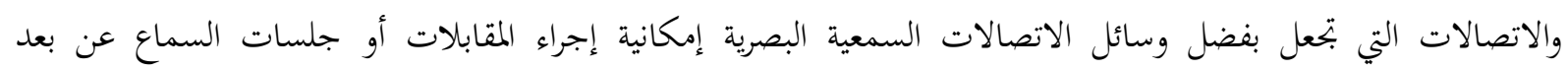
entretiens ou auditions à distance المحامين أو الخبراء، وتقلل من التكاليف (فرج يوسف، ص 41) والمواعيد، وكذلك تنفص من المشاكل الأمنية، هذه المزايا كانت السبب في انتشار استخدام تقنية التحاضر المرئي عن بعد على نطاق واسع في المحاكم الوطنية للدول، وتشجع كل الدول ولئ اليوم

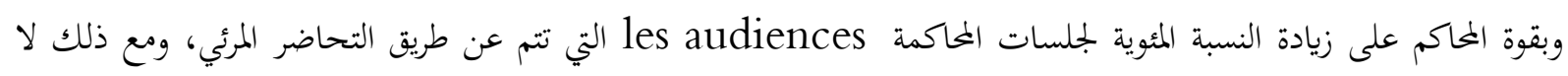

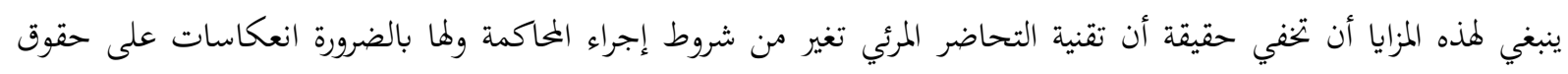

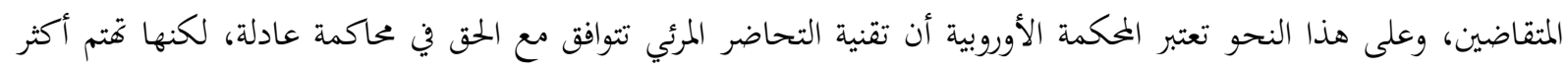

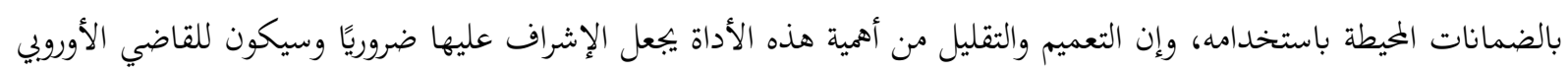

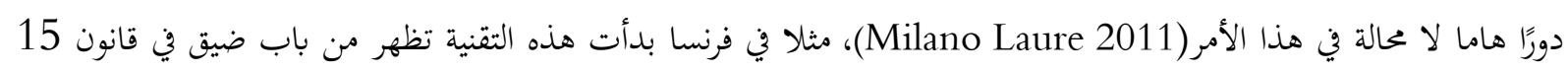

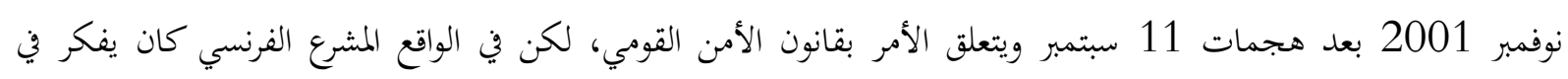

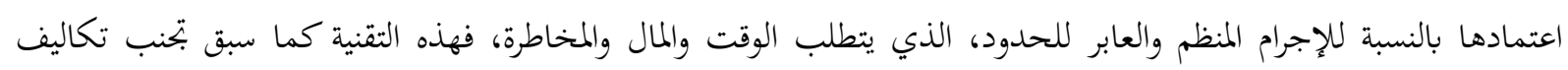

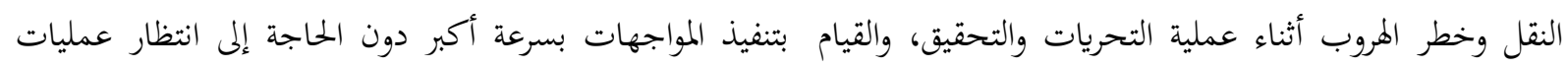

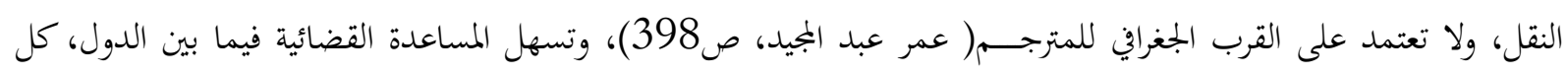

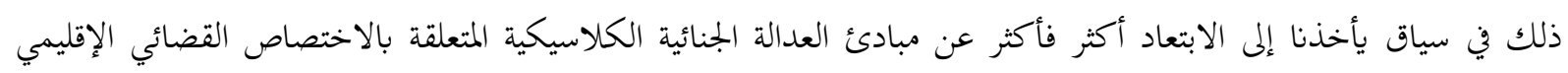

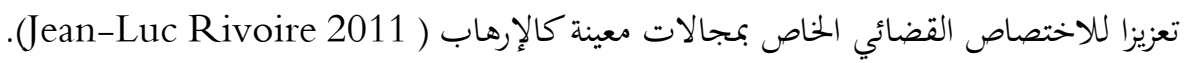


- الفرع الثاني: مزايا التحاضر المرئي عن بعد بالنسبة للمتهم

بصرف النظر عن الجانب النفعي البحت السابق ذكره، قد يتم دفع الأطراف للمطالبة باستخدام تقنية التحاضر المرئي

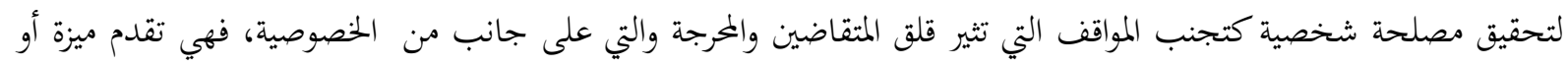

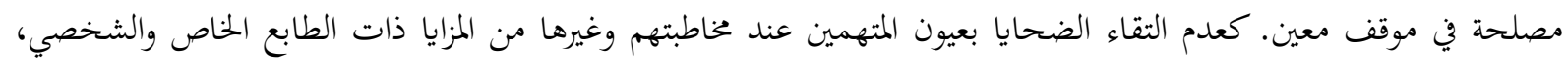

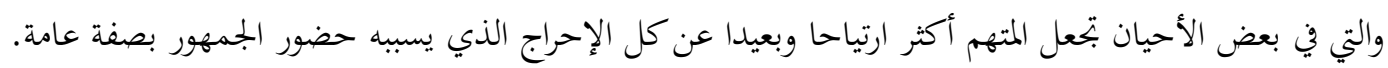

في الأخير ودون إنكار مزايا إجراء المحاكمات الجنائية عبر تقنية التحاضر المرئي عن بعد، وفي ظل التوجه نخو الانتشار

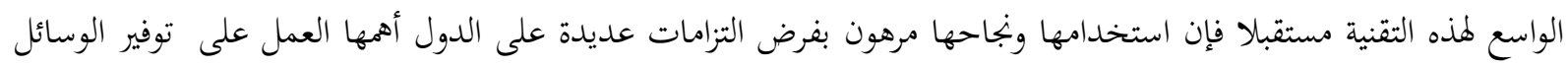

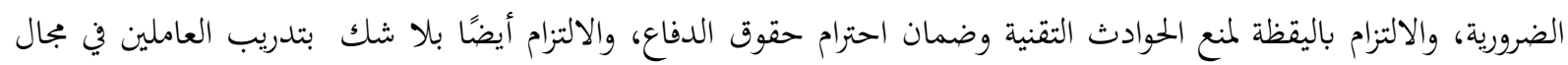
العدالة على هذا النوع من الاتصالات والتقنيات.

وطبعا الأمر دائما متروك للمحكمة من ناحية أن تقتصر استخدام هذه التقنية على قضايا محددة، في حين قد تبقي

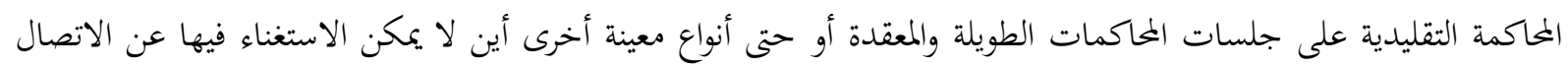

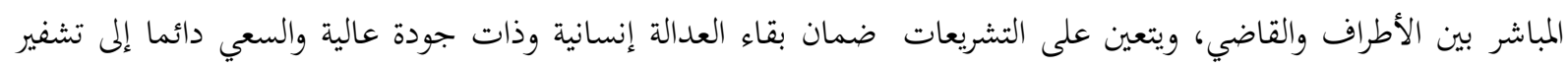
البيانات الشخصية حفاظا على الحق في الخصوصية والسرية.

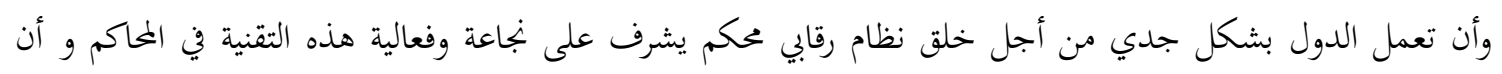
استعمالها يجب أن لا يهدر حقوق الدفاع، حفاظا على المبادئ العامة للمحاكمة العادلة. 


\section{قائمة المراجع باللغة العربية}

- اتفاقيات وقوانين

نظام روما الأساسي للمحكمة الجنائية الدولية المعتمد في روما في 17تموز: يوليه 1998) اتفاقية الأمم المتحدة لمكافحة الجريمة المنظمة عبر الوطنية، اعتمدت بموجب قرار الجمعية العامة للأمم المتحدة الدورة 25 المؤرخ في 15 تشرين

$$
\text { الاتفاقية الأوروبية لحقوق الإنسان، روما في } 04 \text { نوفمبر } 2000 .
$$

الأمر رقم 15-02، المتضمن قانون الإجراءات الجزائية المعدل والمتمم الأمر رقم 66-155، المؤرخ في 08 جوان كوان 1966، 1960، المؤرخ في 23 جويلية

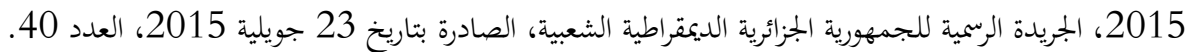

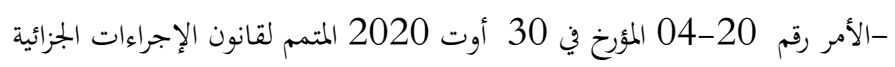

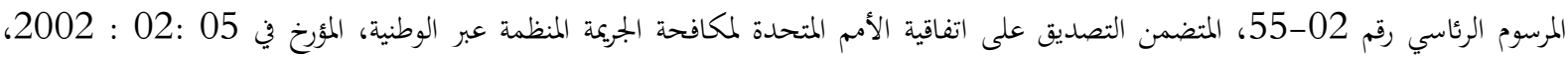

$$
\text { المنشور بتاريخ 10:02: 2002، الجريدة الرسمية للجمهورية الجزائرية، عدد } 09 .
$$

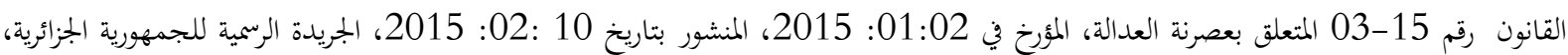
عدد 06.

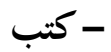

أمير فرج يوسف، المحاكم الالكترونية والتقاضي الالكتروني، المكتب العربي الحديث، القاهرة، 2014.

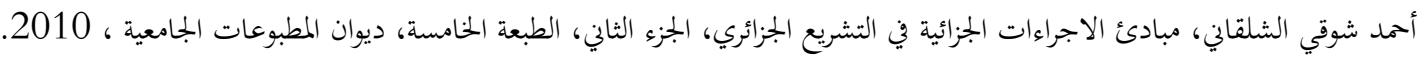

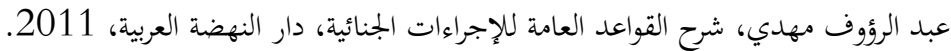

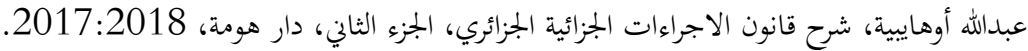
حاتم بكار، حماية حق المتهم في محاكمة عادلة، دراسة تحليلية تأصيلية انتقادية مقارنة في ضوء التشريعات الجنائية (المصرية، الليبية، الفرنسية، الانجليزية، الأمريكية، الشريعة الاسلامية)، منشأة المعارف، الاسكندرية، 1997.

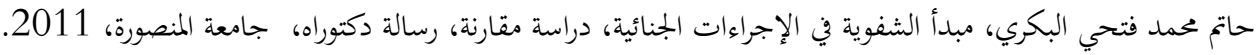
محمد زكي أبو عامر، الإجراءات الجنائية، منشورات الحلبي الحقوقية، الطبعة الأولى، 2010.

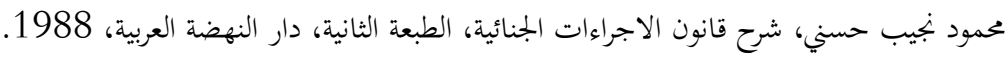

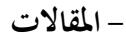

عمر عبد المجيد، ضمانات المحاكمة العادلة على ضوء تقنية الاتصال عن بعد في الاجراءات الجنائية في دولة الامارات، دراسة مقارنة، مجلة القانون الكويتية العالمية، السنة السادسة، العدد4، 2018.

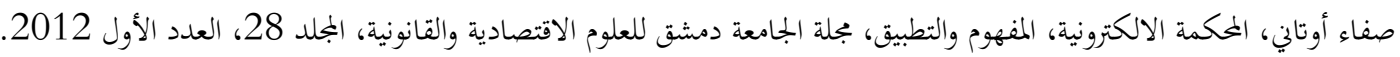

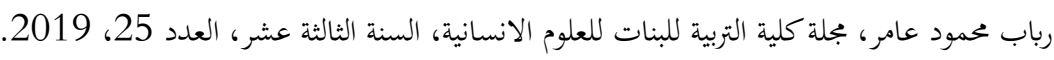
محد العيداني يوسف زروق، رقمنة العدالة في الجزائر على ضوء قانون 15-03، بجلة الباحث للدراسات الاكاديمية، البجلد 07، العدد 01، 2020. 
Antoine Garapon, bien juger, Essais sur le rituel judiciaire,Odile Jacop, Paris,2001.

Dominique Verdeilhan, L'audience est ouverte - Chroniques d'une justice défaillante Éditeur Rocher,2021.

F. Pillot, «La visioconférence. Ethique, modernité, humanité », intervention à la Conférence des Cours d'appel de l'UE).

L. Cadiet, "Le procès civil à l'épreuve des nouvelles technologies », Procédures, avril 2010, Dossier 8).

Laurence Dumoulin et Christian Licoppe, Les audiences à distance, Genèse et institutionnalisation d'une innovation dans la justice, LGDJ-Lextenso édition 2017.

$$
\text { - - عناوين المراجع الالكترونية }
$$

Vers une nouvelle oralité ? Entretien avec internet : voir -, par Jean-Luc RivoireJean Danet

le site internet : https:::www.cairn.info:revue-les-cahiers-de-la-justice-2011-2-page-

73.htm

Visioconférence et droit à un procès équitable, RDLF 2011, chron. $n^{\circ} 08$ Milano Laure,

Marc Janin, http:::www.revuedlf.com:cedh:visioconference-et-droit-a-un-proces-equitable.

La visioconférence à l'épreuve du procès équitable, Les Cahiers de la Justice -

Voir le site : https:::www.cairn.info:revue-les-cahiers-de-la-justice-2011. 